\title{
RMetS
}

Royal Meteorological Society

\section{Assessing the impact of pre-GPM microwave precipitation observations in the Goddard WRF ensemble data assimilation system}

\author{
Philippe Chambon ${ }^{\mathrm{a}, \mathrm{b}}$, Sara Q. Zhang ${ }^{\mathrm{b} *}$ Arthur Y. Hou ${ }^{\mathrm{b}}$, Milija Zupanski ${ }^{\mathrm{c}}$ and Samson Cheung ${ }^{\mathrm{d}}$ \\ ${ }^{a}$ Universities Space Research Association, Columbia, MD, USA \\ ${ }^{\mathrm{b}}$ NASA Goddard Space Flight Center, Laboratory for Atmospheres, Greenbelt, MD, USA \\ ${ }^{\mathrm{c}}$ Cooperative Institute for Research in the Atmosphere, Colorado State University, Fort Collins, CO, USA \\ ${ }^{\mathrm{d}}$ Department of Mathematics, University of California, Davis, CA, USA \\ ${ }^{\star}$ Correspondence to: S. Q. Zhang, NASA Goddard Space Flight Center, Code 612, Greenbelt, MD 20771, USA. \\ E-mail: sara.q.zhang@nasa.gov \\ This article has been contributed to by US Government employees and their work is in the public domain in the USA
}

The forthcoming Global Precipitation Measurement (GPM) Mission will provide nextgeneration precipitation observations from a constellation of satellites. Since precipitation by nature has large variability and low predictability at cloud-resolving scales, the impact of precipitation data on the skills of mesoscale numerical weather prediction (NWP) is largely affected by the characterization of background and observation errors and the representation of nonlinear cloud/precipitation physics in an NWP data assimilation system.

We present a data impact study on the assimilation of precipitation-affected microwave (MW) radiances from a pre-GPM satellite constellation using the Goddard WRF Ensemble Data Assimilation System (Goddard WRF-EDAS). A series of assimilation experiments are carried out in a Weather Research Forecast (WRF) model domain of $9 \mathrm{~km}$ resolution in western Europe. Sensitivities to observation error specifications, background error covariance estimated from ensemble forecasts with different ensemble sizes, and MW channel selections are examined through single-observation assimilation experiments. An empirical bias correction for precipitation-affected MW radiances is developed based on the statistics of radiance innovations in rainy areas. The data impact is assessed by full data assimilation cycling experiments for a storm event that occurred in France in September 2010. Results show that the assimilation of MW precipitation observations from a satellite constellation mimicking GPM has a positive impact on the accumulated rain forecasts verified with surface radar rain estimates. The case-study on a convective storm also reveals that the accuracy of ensemble-based background error covariance is limited by sampling errors and model errors such as precipitation displacement and unresolved convective scale instability.

Key Words: precipitation; ensemble data assimilation; microwave observations; forecasts verification; Global Precipitation Measurement Mission

Received 12 December 2012; Revised 7 June 2013; Accepted 12 June 2013; Published online in Wiley Online Library 30 September 2013

\section{Introduction}

Precipitation plays key roles in the global and regional hydrological cycles. It is also a difficult environmental variable to be modelled and predicted in modern-era numerical weather prediction (NWP) systems. One critical problem in the relatively low accuracy of rain forecasts is that precipitation processes are highly nonlinear with large variability in time and spatial scales, therefore small errors in initial conditions can lead to a large divergence in outcomes. To improve our knowledge of the initial conditions of precipitation forecasts, we need to collect observations and use data information to infer the conditions of precipitation processes as well as the associated uncertainty. In the last decade, measurements from the Tropical Rainfall Measuring Mission (TRMM) have helped promote the use of satellite precipitation data to improve modelling of precipitation processes as well as initial conditions for forecasts. The assimilation of satellite precipitation data in global NWP systems has been shown to improve weather and hydrological forecasts as well as climate analyses (Marécal and Mahfouf, 2002; Hou et al., 2004; Mahfouf et al., 2005; Hou and Zhang, 2007; Bauer et al., 2010).

However, special challenges remain in the assimilation of space-borne observations of cloud and precipitation (Errico et al., 2007; Bauer et al., 2011). The most outstanding issue is how to represent errors in background states associated with precipitation processes and in precipitation-affected radiance 
observations. It is evident that the background error covariance needs to represent the flow-dependent forecast uncertainty associated with evolving precipitation processes, particularly when hydrometeor variables are included in the analysis procedure. Michel et al.(2011) developed a binning method to compute separate background error covariance for precipitating and non-precipitating areas. Their comparison study provides statistical structure of heterogeneous forecast error covariance with shorter horizontal error correlations in precipitating areas, and vertical correlations mimicking the cloud vertical extension by the convection processes. Geer and Bauer (2011) analysed the statistical property of the first guess (FG) departures of all-sky microwave (MW) radiances over ocean surface. They found the dependence of FG departure standard deviations on so-called symmetric cloud amount. From that, they derived an observation error model to take into account non-Gaussian effects unique to cloud and precipitation-related observations. The bias correction on precipitation-affected radiance observations remains a difficult problem. Unlike observations under clear-sky conditions, precipitation-affected radiances are prone to situation-dependent errors, such as poor approximations of physical properties of hydrometeors in radiative transfer calculations and model cloud physics (Lang et al., 2011; Johnson et al., 2012).

In recent years, there have been considerable advances in the development of ensemble data assimilation techniques. Some successes in assimilation of remote-sensed observations, such as airborne Doppler radar radial velocity or MW radiances have demonstrated strong evidence of improved forecast skills and analysis accuracy (Schwartz et al., 2012; Weng and Zhang, 2012). However, ensemble assimilation application of remote-sensed cloud and precipitation data is scarce, mostly at the stage of synthetic observations in an idealized experiment environment (Pincus et al., 2011; Zupanski et al., 2011a). Ensemble approaches estimate the flow-dependent background error covariance based on an ensemble of forecasts, and use an ensemble of nonlinear forward model simulations to link model space and observed space. Taking advantage of these properties of ensemble assimilation framework, the Goddard Weather Research Forecast (WRF) Ensemble Data Assimilation System (Goddard WRFEDAS) has been developed to assimilate precipitation-affected MW radiances from satellite instruments (Zupanski et al., 2011b). This system uses the WRF model with National Aeronautics and Space Administration (NASA) microphysics (Tao, 2003), the Goddard Satellite Data Simulator Unit (G-SDSU:Matsui et al., 2009) for the observation operator of cloud/precipitationsensitive radiance, and a maximum likelihood ensemble filter (Zupanski, 2005; Zupanski et al., 2008). Zhang et al.(2013) evaluated the analysis system performance of the Goddard WRFEDAS and examined data impact by assimilating data of the TRMM Microwave Imager (TMI) and the Advanced Microwave Scanning Radiometer for EOS (AMSR-E) in a tropical storm after landfall and a heavy rain event in the southeast region of the United States. They found that storm intensity in the analysis is enhanced and short-term forecasts of accumulated surface rainfall are improved, an indication of the benefit of using precipitation information from radiances and ensemble-based forecast error covariance.

The international Global Precipitation Measurement (GPM) Mission to be launched in 2014 will provide the next-generation observations of precipitation with additional observation coverage (Hou et al., 2008). The GPM Core Observatory will collect coincident passive and active MW measurements from the GPM Microwave Imager (GMI) and the Dual-frequency Precipitation Radar (DPR). These observations will provide further insights on precipitation processes and establish a transfer standard to improve the accuracy and consistency of precipitation estimates from a constellation of satellites contributed by a consortium of international partners (see http://pmm.nasa.gov/). In this article, we extend the application of the Goddard WRF-EDAS to assimilate precipitation data from a pre-GPM constellation to examine: (i) the bias in precipitation-affected MW radiances over land surface, (ii) the extent to which the ensemble algorithm is able to capture synoptic features in background error covariance, and (iii) the impact on precipitation forecasts of assimilating data with a coverage similar to the GPM constellation. In section 2 we give a system overview of the Goddard WRFEDAS. In section 3 we describe the satellite data to be assimilated and an off-line bias correction scheme for precipitation-affected radiance. In section 4 we use single-observation experiments to examine the flow-dependent structure of background error covariance and analysis sensitivity. In section 5 we present the results of assimilating constellation MW data in a heavy rain event in France and discuss the implication of data impact. Finally, a summary is given and perspectives for future research are discussed in section 6 .

\section{Assimilation system}

The Goddard WRF-EDAS solves a maximum likelihood estimation problem based not only on available observations at the current time, but also on model forecasts initialized from the previous analysis (Zupanski, 2005; Zupanski et al., 2008). The system consists of a forecast and analysis cycle. The forecast step provides the background state, defined as the WRF model integration forward in time from $t_{n-1}$ to $t_{n}$ (an analysis interval):

$$
\mathbf{x}_{n}^{\mathrm{f}}=M\left(\mathbf{x}_{n-1}^{\mathrm{a}}\right) .
$$

The analysis step is performed after the forecast and defined as the maximum likelihood solution to the cost function:

$J(\mathbf{x})=\frac{1}{2}\left[\mathbf{x}-\mathbf{x}^{\mathrm{f}}\right]{ }^{\mathrm{T}} \mathbf{P}_{\mathrm{f}}^{-1}\left[\mathbf{x}-\mathbf{x}^{\mathrm{f}}\right]+\frac{1}{2}[\mathbf{y}-h(\mathbf{x})]^{\mathrm{T}} \mathbf{R}^{-1}[\mathbf{y}-h(\mathbf{x})]$,

where $[\mathbf{y}-h(\mathbf{x})]$ is the FG departure (the discrepancy between observation and model simulation), with nonlinear observation operator $h$. The analysis increment on the current state is expressed by $\left[\mathbf{x}^{\mathrm{a}}-\mathbf{x}^{\mathrm{f}}\right]$. The background error covariance is denoted as $\mathbf{P}_{\mathrm{f}}$, and the observation error covariance as $\mathbf{R}$. The analysis variable $\mathbf{x}$ includes hydrometeors (mixing ratio of rainwater, snow, graupel, cloud water and cloud ice from model microphysics) in addition to other dynamical variables. Corresponding forecast errors in precipitation and clouds are estimated simultaneously with that of the wind, temperature, moisture and pressure fields.

In the Goddard WRF-EDAS, the observation error covariance $\mathbf{R}$ is prescribed. The background error covariance $\mathbf{P}_{\mathrm{f}}$ is dynamically estimated using an ensemble of perturbed forecasts so that the forecast error information is flow-dependent and updated to current meteorological conditions. A localization scheme is employed to reduce the sampling errors associated with the given finite ensemble size (Yang et al., 2009). A compactly supported covariance function (Gaspari and Cohn, 1999) is applied to specify the error decorrelation, for instance it is set at $45 \mathrm{~km}$ in the experiments with $9 \mathrm{~km}$ model resolution. The analysis problem is solved in ensemble subspace with a variable transformation:

$$
\mathbf{x}-\mathbf{x}^{\mathrm{f}}=\mathbf{P}_{\mathrm{f}}^{\frac{1}{2}}\left[\mathbf{I}+\mathbf{Z}^{\mathrm{T}} \mathbf{Z}\right]^{(-1 / 2)} \zeta
$$

where $\zeta$ is the new transformed variable. With $\mathbf{P}_{i}^{\mathrm{f}}$ being the $i$ th column of $\mathbf{P}_{\mathrm{f}}^{\frac{1}{2}}$, the $i$ th column of the observation perturbation matrix $\mathbf{Z}$ is defined as:

$$
\mathbf{z}_{i}=\mathbf{R}^{(-1 / 2)}\left[h\left(\mathbf{x}^{\mathrm{f}}+\mathbf{p}_{i}^{\mathrm{f}}\right)-h\left(\mathbf{x}^{\mathrm{f}}\right)\right] .
$$

With the ensemble filter formulation, full nonlinear observation operators are used here. For a more detailed overview of the Maximum Likelihood Ensemble Filter algorithm, see Zupanski et al. (2011b). 
Table 1. MW level-1 radiance data selected for the study.

\begin{tabular}{|c|c|c|c|c|c|}
\hline Satellite & Instrument & Scanning method & $\begin{array}{l}\text { Equator crossing time } \\
(\mathrm{ECT}) \text { ascending node }\end{array}$ & $\begin{array}{l}\text { Channels selected for } \\
\text { assimilation (along track } \times \\
\text { cross track resolution) }\end{array}$ & $\begin{array}{l}\text { Channels selected for } \\
\text { additional information } \\
\text { (scattering index over land } \\
\text { computation) }\end{array}$ \\
\hline DMSP-F16 & SSMI-S & Conical & $18: 51$ & $\begin{array}{l}91.6 \mathrm{H}(14 \times 13 \mathrm{~km}) \\
91.6 \mathrm{~V}(14 \times 13 \mathrm{~km}) \\
150.0 \mathrm{H}(14 \times 13 \mathrm{~km}) \\
183.3 \pm 7 \mathrm{H}(14 \times 13 \mathrm{~km})\end{array}$ & $\begin{array}{l}19.3 \mathrm{~V}(73 \times 47 \mathrm{~km}) \\
22.2 \mathrm{~V}(73 \times 47 \mathrm{~km})\end{array}$ \\
\hline DMSP-F18 & SSMI-S & Conical & 20:08 & Same as above & Same as above \\
\hline AQUA & AMSR-E & Conical & $13: 30$ & $\begin{array}{l}89 \mathrm{H}(6 \times 4 \mathrm{~km}) \\
89 \mathrm{~V}(6 \times 4 \mathrm{~km})\end{array}$ & $\begin{array}{l}18.7 \mathrm{~V}(27 \times 16 \mathrm{~km}) \\
23.8 \mathrm{~V}(32 \times 18 \mathrm{~km})\end{array}$ \\
\hline NOAA-18 & MHS & Cross track & $14: 22$ & $\begin{array}{l}89.0(16 \times 16 \mathrm{~km} \text { at nadir }) \\
157.0(16 \times 16 \mathrm{~km} \text { at nadir }) \\
190.3(16 \times 16 \mathrm{~km} \text { at nadir })\end{array}$ & - \\
\hline NOAA-19 & MHS & Cross track & $13: 32$ & Same as above & - \\
\hline Metop-A & MHS & Cross track & $21: 30$ & Same as above & - \\
\hline
\end{tabular}

The Advanced Research WRF (ARW) model is incorporated in the assimilation system with mesoscale NWP configuration (Skamarock et al., 2005). Operational global analyses from the National Center for Environmental Prediction Global Forecast System (NCEP GFS) provide lateral boundary conditions for the limited-area forecasts. For all the experiments in this article the model is configured as non-hydrostatic at the spatial resolution of $9 \mathrm{~km}$ grid spacing over a domain spanning from $10^{\circ} \mathrm{W}$ to $20^{\circ} \mathrm{E}$ and 35 to $52^{\circ} \mathrm{N}$. The cloud and precipitation processes are modelled by a one-moment bulk microphysical scheme based on the Goddard Cumulus Ensemble (Tao, 2003).

For satellite radiance observations, the observation operator consists of spatial interpolation and Radiative Transfer Model (RTM) constructed from G-SDSU. MW radiances are simulated by a delta-Eddington two-stream radiative transfer model with slant path view (Kummerow et al., 1996). The parameters for particle size distribution (PSD) are prescribed to be consistent with those in the model cloud physics. The assumptions for the physical properties of ice-phase hydrometeors are a soft sphere with ice as an inclusion within an air matrix. To account for the variability within a field of view (FOV) of the satellite instrument measurement at pixel resolution, the simulated brightness temperatures are calculated first at each model grid point, then are convoluted to the FOV of each observation to form a pixel-equivalent $\mathrm{FG}$ radiance to be compared to the observation. Where the observations are over land, the National Environmental Satellite Data and Information Service (NESDIS) emissivity model is used to estimate the surface emissivity at required frequencies using surface characteristics and variables provided by the WRF background (Weng et al., 2001).

\section{MW data in precipitating regions}

\subsection{Observations to be assimilated}

A pre-GPM constellation of satellites provides MW observations of precipitation for a domain in western Europe. Data from seven satellites are available for the data assimilation period. All observations are in the form of Level-1 radiance at native sampling resolutions. Brightness temperature data from Special Sensor Microwave Imager/Sounder (SSMIS) on board DMSPF16, -F17 and -F18 satellites are processed and inter-calibrated as a beta version of the Colorado State University (CSU) Fundamental Climate Data Record (Sapiano et al., 2012). Data from Advanced Microwave Scanning Radiometer for EOS (AMSR-E) on board Aqua, and Microwave Humidity Sounder (MHS) on board NOAA-18, -19 and Metop-A are also included. Table 1 summarizes the characteristics of precipitation-sensitive MW radiance data used in this study. Figure 1 shows Cumulated Distribution Functions (CDF) of time intervals between two consecutive observations from two different constellations of satellites, normalized by the total observations in each $1^{\circ}$ latitude band, are shown as function of latitudes ((a) and (c) panels). The CDF are built from 90-day orbit simulations computed using the IXION software (Capderou, 2005). For a given observing system, each time its swath crosses a $1^{\circ}$ by $1^{\circ}$ area is considered as one observation for the $1^{\circ}$ domain; probability distribution functions (PDFs) of time intervals between consecutive observations are then computed for each $1^{\circ}$ area over the latitude from 0 to $70^{\circ}$, and the longitude $\left(0^{\circ} \mathrm{E} ; 1^{\circ} \mathrm{E}\right)$. Note that over a 90 -day period a different longitude would give similar results; results are also symmetric for the Northern and Southern Hemisphere. Such a constellation leads to data coverage of $12-14$ observations per day in the midlatitudes $\left(40-50^{\circ} \mathrm{N}\right)$ with about $50 \%$ of the time intervals between consecutive observations at the same location shorter than $1 \mathrm{~h}$ (Figure 1(a)). A GPM constellation as foreseen by 2014 will lead to 19 observations per day over the same latitudes, more than $70 \%$ of the time with intervals shorter than $1 \mathrm{~h}$ (Figure 1(b)).

For precipitation assimilation experiments using MW radiances over land surfaces, high-frequency channels are selected for their sensitivity to hydrometeor scattering and relative insensitivity to land surface emissivity. However, several low-frequency channels are used to calculate a Scattering Index over Land (SIL) to detect precipitating conditions (Grody, 1991). Data from crosstrack MHS is sampled to use only pixels with scanning angles smaller than $40^{\circ}$ from nadir. The datasets used in the assimilation experiments cover a 3-day period from 6 September 2010 to 8 September 2010. Additionally, 8 months of SSMIS data (September to December periods in 2010 and 2011 over western Europe) are used in statistical calculations for bias correction and error analysis.

\subsection{Observation errors}

In any data assimilation system based on an optimal estimation framework, thorough knowledge of observation errors is as important as the observation measurements themselves. In the following subsections we discuss the bias and error covariance for precipitation-affected MW radiances.

\subsubsection{Bias correction to precipitation-affected MW radiances}

Bias potentially affects analysis accuracy in data assimilation (Dee, 2005). Various bias correction methods have been developed and implemented in operational data assimilation systems. The most widely used is the variational adaptive bias correction applied to clear-sky satellite radiances observations with selected model variables as predictors (Dee, 2004; Auligné et al., 2007). However, this approach may not be well suited to cloudy and 

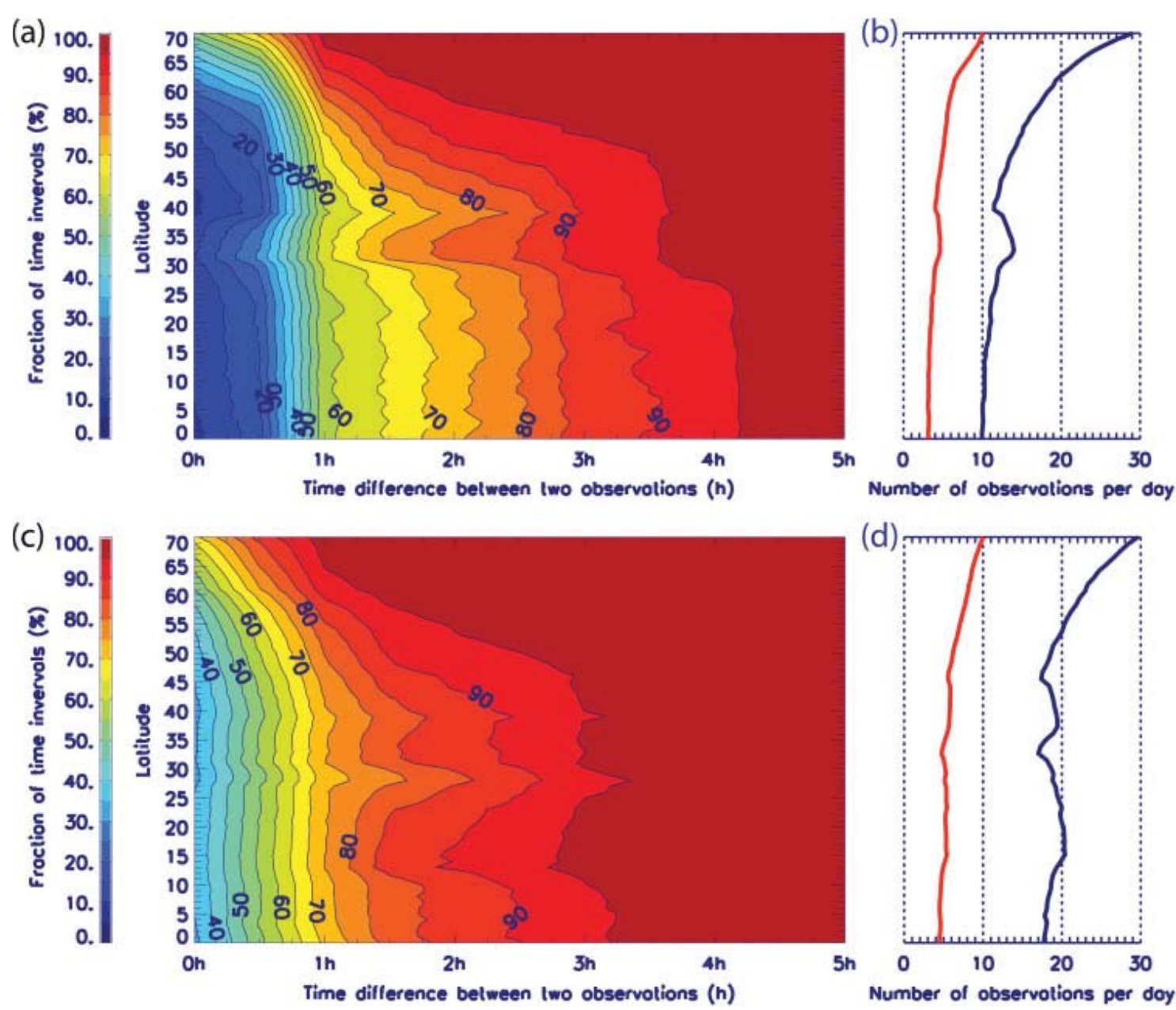

Figure 1. (a), (c) Cumulated distribution functions of time intervals between two consecutive observations from two different constellations of satellites, normalized by the total observations in each $1^{\circ}$ latitude band, are shown as a function of latitude. The constellation considered for the top panel simulates the pre-GPM constellation as available in 2010 (DMSP-F16, -F17, -F18, AQUA, TRMM, NOAA-18, NOAA-19 and Metop-A); the constellation for the bottom panel simulates the GPM constellation as foreseen in 2014 (F16, F17, F18, F19, F20, GCOM-W1, TRMM, Megha-Tropiques, GPM-Core, NOAA-18, NOAA-19, Metop-A and NPP). On the (b) and (d) panels, the blue curves show the mean number of observations per day for both constellations as a function of latitude, and the red curves show the mean number of observations assimilated with $3 \mathrm{~h}$ cycles and $1 \mathrm{~h}$ assimilation windows. This figure is available in colour online at wileyonlinelibrary.com/journal/qj

rainy areas if using the same predictors as those for clear-sky conditions. A bias between the observed and the FG radiance under precipitating conditions can arise from systematic model errors and observational errors. Biases can occur in instrument measurements because of satellite orbital drift, varying scan geometry or poor calibration (Bell et al., 2008). Inaccuracies in RTM with assumptions and approximations of hydrometeor properties can cause biases in simulated radiances (Petty and Huang, 2010). Uncertainty in land surface emissivity and skin temperature can introduce biases in FG radiances (English, 2008). Numeric weather prediction models are imperfect and often misplace rain locations or produce excess/shortage of clouds and precipitation in the background state, and these biases are projected to the observation space (Lang et al., 2011). Furthermore, a so-called asymmetric sampling bias can occur if predictors in the error model are based on either FG or observed cloudiness (Bauer et al., 2010). A non-zero mean of FG departures of precipitation-affected radiances represents the combined bias from any error sources noted above. A bias correction for precipitation-affected radiances should be designed to avoid asymmetric sampling bias and correct only the biases in observations and RTM, without attributing systematic model errors to observations.

Geer and Bauer (2011) demonstrated a mean cloudiness sampling method in the formulation of a symmetric error model for all-sky low-frequency MW radiance. The predictor is the average of the cloud amount of FG and the cloud amount of observation. They also recommended mean cloud amount as a predictor for bias correction to avoid an asymmetric sampling problem. Lopez (2011) applied this approach and used a symmetric predictor for bias correction of radar and gauge precipitation data in the European Centre for Mediumrange Weather Forecasts (ECMWF) global Integrated Forecasting System. To determine if there is a similar dependence of FG departure bias at MW high frequencies on the strength of precipitation signals both in FG and observed radiance, FG departures of SSMIS are collected from various meteorological conditions that occurred in western Europe during the 2010 and 2011 September-December periods. For this purpose, WRF simulations are performed at $9 \mathrm{~km}$ resolution in this region, and reinitialized every day. The RTM is used to simulate FG radiances at the same frequencies and same geolocations as SSMIS observations. A Scattering Index over Land (henceforth SIL), originally developed for MW precipitation retrieval algorithms over land (Grody, 1991; Wilheit et al., 2003), is used to identify precipitation signatures and sample the FG departures. Figure 2(a) shows the FG departure bias at $150 \mathrm{GHz}$ binned as a function of SIL for observations ( $\mathrm{SIL}_{\mathrm{OBS}}$ ) and $\mathrm{FG}\left(\mathrm{SIL}_{\mathrm{FG}}\right)$. This figure illustrates the aforementioned mixture of biases from forecast and observations. When $\mathrm{SIL}_{\mathrm{FG}}$ is greater than $\mathrm{SIL}_{\mathrm{OBS}}$, the positive bias ranges up to $70 \mathrm{~K}$. On the other hand, when SIL $_{\mathrm{FG}}$ is lower than SIL $_{\mathrm{OBS}}$, the bias is negative with a minimum of $-75 \mathrm{~K}$. In situations where observations and FG simulations agree on scattering condition as represented by the samples along the 

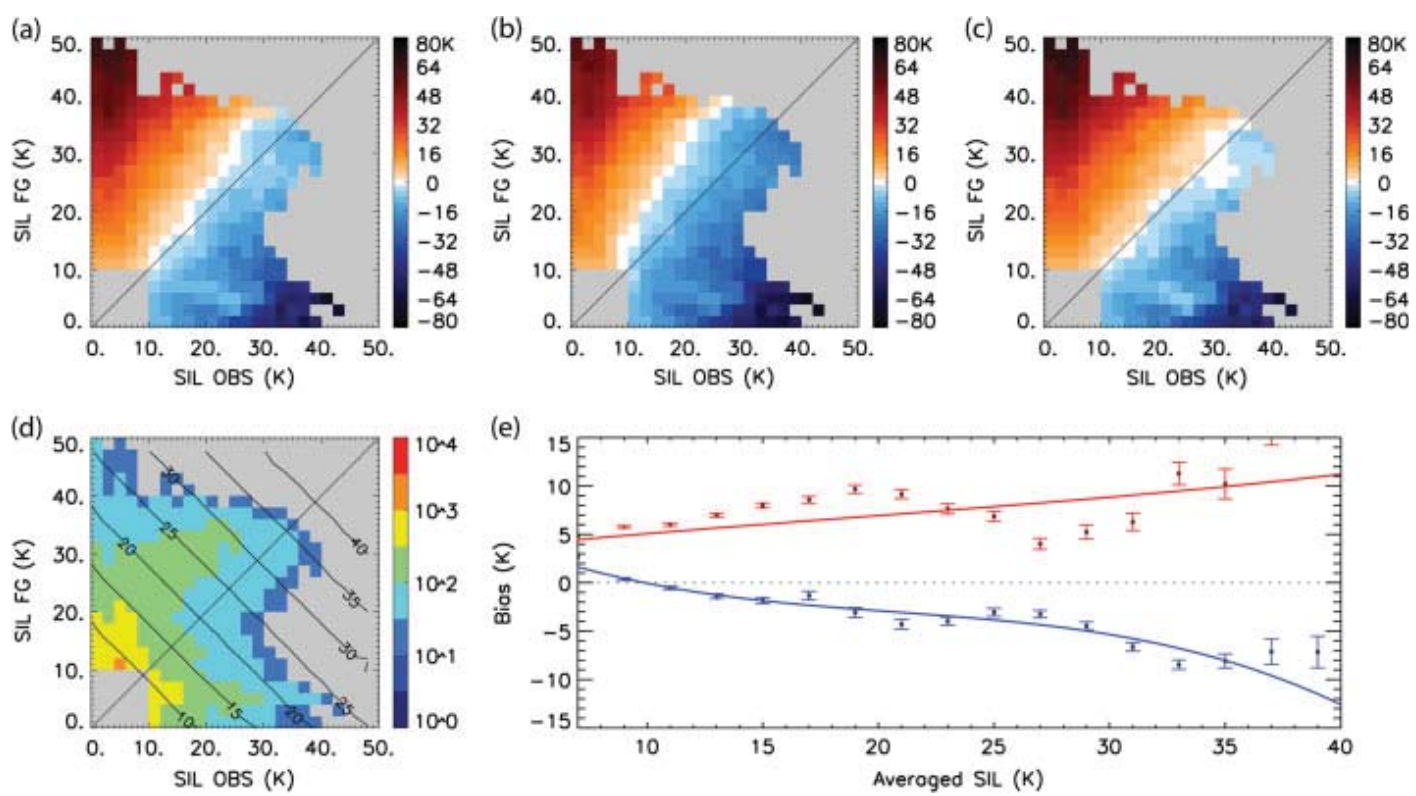

Figure 2. Bias of FG departures between SSMIS observations at $150 \mathrm{GHz}$ and model forecast as function of SIL $\mathrm{FG}_{\text {and SIL }}$ OBS: (a) before bias correction, (b) after bias correction taking into account all samples, and (c) after bias correction taking into account only the samples with similar SIL. (d) Number of samples (on log scale) collected during the September-December periods in 2010 and 2011, with grey areas for bins where less than 30 samples have been collected, grey areas where both SIL $_{\mathrm{FG}}$ and SIL $\mathrm{OBS}$ are lower than $10 \mathrm{~K}$, and black contour lines representing the SIL $_{\mathrm{AVG}}$ value as function of SIL $_{\mathrm{FG}}$ and $\mathrm{SIL}_{\mathrm{OBS}}$. (e) Bias correction with SIL $\mathrm{AVG}_{\text {a }}$ predictor; the red curve represents the bias correction model taking into account all samples, the blue curve represents the bias correction model taking into account only the samples with similar SIL, error bars indicate the standard deviation of estimation of empirical bias computed for each bin of SIL AVG.

diagonal of Figure 2(a), biases are persistently negative and the absolute value increases with increasing SIL. In addition to this asymmetry along the diagonal line in Figure 2(a), there is a second asymmetry in terms of scattering occurrence shown in Figure 2(d) indicating an excessive frequency of high scattering index samples in FG.

To avoid the asymmetric sampling problem, we use an averaged Scattering Index as the predictor for an empirical bias correction model. A third-degree polynomial is used to fit the empirical bias values. A set of polynomial coefficients is computed; the derived bias correction model, shown as the red curve in Figure 2(e) for the $150 \mathrm{GHz}$ channel, increases from $4 \mathrm{~K}$ for low SIL $_{\mathrm{AVG}}$ up to $15 \mathrm{~K}$ as SIL $_{\mathrm{AVG}}$ increases to $40 \mathrm{~K}$.

However, this bias correction based on all FG departure sampling fails to reduce the bias effectively; the bias in the area of similar $\operatorname{SIL}_{\mathrm{AVG}}$ (along the diagonal) becomes larger as shown in Figure 2(b). Indeed, the bias correction encounters two underlying asymmetries in the FG departure distribution. The first is the warm bias of FG brightness temperatures indicated by the consistent negative values along the diagonal. The second is the excessive scattering occurrence frequency in FG corresponding to mismatched precipitation situations as shown in Figure 2(d). These biases can be caused by systematic errors in the RTM, or by the excessive ice-phase precipitation in the background state, or, alternatively, by a combination of the two. We examine this issue by a sensitivity experiment altering assumptions and approximations in radiative transfer calculations for high frequencies sensitive to ice-phase hydrometeors. Changing the soft sphere approximation to non-spherical ice crystals (Liu, 2008) deepens the brightness temperature depression in the order of $-3 \mathrm{~K}$ in $91 \mathrm{~V}$ and $-5 \mathrm{~K}$ in $150 \mathrm{GHz}$. This change in simulated brightness temperatures associated with the Mie sphere approach is consistent with the warm bias shown in Figure 2(a). For the bias of high occurrence of scattering in FG illustrated in Figure 2(d), there are ice-phase hydrometeors in abundance in the background state. The high occurrence frequency of scattering FG likely results from the systematic bias in model-simulated ice contents due to uncertainties in hydrometeor parameters prescribed in WRF model physics and RTM. For example a change of the intercept of snow particle size distribution (PSD) from a fixed value to being temperature-dependent leads to as much as a $10 \mathrm{~K}$ increase in simulated $91 \mathrm{~V}$ brightness temperatures in the precipitating area. The high scattering occurrence bias is dominant, if all samples are used. When coefficients of the bias model are derived without discriminating among model errors and observation biases, degradation is indeed caused by applying the bias correction to FG departures as shown in Figure 2(b).

To avoid attributing systematic model errors in the background state to observations, we limit the samples for estimating bias correction polynomial coefficients to those along the 1:1 line in Figure 2(a). It is here that observations and FG are in agreement with precipitating conditions. In this work, a $5 \mathrm{~K}$ tolerance between SIL $_{\mathrm{OBS}}$ and SIL $_{\mathrm{FG}}$ was selected. A set of bias correction model parameters is computed using this sampling strategy; the numerical values of the polynomial coefficients are reported in Table 2 for each selected SSMIS channel. The blue curve in Figure 2(e) depicts this bias correction model as a function of SIL $_{\mathrm{AVG}}$, with error bars indicating the standard deviation of estimation for each bin of averaged SIL. The error becomes greater when fewer samples are available in the regime of highend averaged SIL. As shown in Figure 2(c), the FG departure distribution after this bias correction reduces the bias in higher scattering situations, with overall bias along the diagonal reduced to $0.09 \mathrm{~K}$ from $-1.6 \mathrm{~K}$ in the original distribution.

The bias correction model presented in this section is a first attempt to correct precipitation-affected observation biases with a symmetric predictor $\mathrm{SIL}_{\mathrm{AVG}}$. In the assimilation experiments in this article, the empirical bias correction is applied to MW radiance FG departures before the analysis step in assimilation cycling. Systematic errors in land surface emissivity and skin

Table 2. Coefficients of the third-degree polynomials used for the bias correction of the four selected SSMIS channels.

\begin{tabular}{lrcrr}
\hline & $\mathrm{a}_{0}(\mathrm{~K})$ & $\mathrm{a}_{1}$ (no unit) & $\mathrm{a}_{2}\left(\mathrm{~K}^{-1}\right)$ & $\mathrm{a}_{3}\left(\mathrm{~K}^{-2}\right)$ \\
\hline $91 \mathrm{H} \mathrm{GHz}$ & 0.55 & -0.43 & 0.024 & -0.00037 \\
$91 \mathrm{~V} \mathrm{GHz}$ & -2.78 & 0.44 & -0.014 & 0.00007 \\
$150 \mathrm{H} \mathrm{GHz}$ & 8.36 & -1.29 & 0.054 & -0.00087 \\
$183 \pm 7 \mathrm{H} \mathrm{GHz}$ & -0.17 & 0.18 & -0.005 & -0.00002 \\
\hline
\end{tabular}


temperature are important factors for MW radiance assimilation over land. Currently this bias correction only applies to observations in channels with relatively weak sensitivity to land surface and to those under precipitating conditions indicated either by FG or observed radiances. However, in the category of nonprecipitating FG and precipitating observation, the simulated FG brightness temperatures may be under clear-sky conditions. The bias correction of samples in this category should take land surface factors into consideration. Further development of the radiance bias correction will need to take into account all-sky situations.

\subsubsection{Observation error covariance}

Observation error covariance in radiance assimilation accounts for errors from MW measurements and from the RTM. It also includes model physics errors projected to radiance space under precipitating conditions. In practice the observation error covariance is prescribed based on the statistical properties of FG departures that represent the total errors of observation and forecast in radiance space. In contrast with radiance observations under clear-sky conditions, FG departures of precipitationaffected radiances exhibit large variability reflecting discrepancies between observed and FG brightness temperatures in terms of precipitation intensity and location. Figure 3(a) shows the distribution of the root-mean-square error of FG departures sampled with a range of scattering index SILFG and SIL $\mathrm{LBS}_{\mathrm{F}}$ varying from very light precipitation to heavy precipitation with strong scattering $(10 \mathrm{~K}<\mathrm{SIL}<50 \mathrm{~K})$. Along the diagonal line where observations and FG agree on precipitating conditions, root-mean-square errors are about $10-15 \mathrm{~K}$. The larger errors are distributed in the areas where the forecast is clear while the observation detects precipitation, or vice versa. This is often a consequence of displacements in model precipitation or unresolved convective-scale instability. These errors constitute the heavy tails in the distribution of FG departures, which the Gaussian assumption may not be able to represent properly. Therefore the data in these situations will either be rejected by quality control or be included pragmatically by prescribing a large observation error standard deviation.

Similar to the all-sky radiance error model developed by Geer and Bauer (2011) with averaged cloud amount as the predictor, an observation error model can be formulated as a function of averaged SIL with symmetric sampling. Figure 3(b) illustrates the dependency of error standard deviations of SSMIS
$150 \mathrm{GHz}$ channel FG departures to the averaged SIL from SIL $\mathrm{FG}_{\mathrm{F}}$

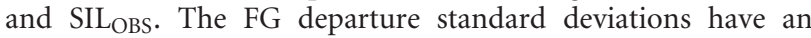
approximately linear relationship with the $\mathrm{SIL}_{\mathrm{AVG}}$, with the lower bound at around $15 \mathrm{~K}$ and the high end at around $55 \mathrm{~K}$. The observation error model is derived as a fraction of the empirically fitted piecewise function shown as the blue line in the same panel. This observation error model is tested in an assimilation experiment using SSMIS radiances. However, the test results give little evidence that $\mathrm{SIL}_{\mathrm{AVG}}$-dependent radiance observation error covariance improves analysis and forecast when compared to the results using a constant value of $25 \mathrm{~K}$ assigned to all observations under precipitating conditions (not shown). For the experiments in the following sections, we choose to specify a constant value for the observation error standard deviation in precipitating regions based on the PDF of FG departures as shown in Figure 3(c). The observation error covariance is set as a diagonal matrix, with no error correlation between observations.

\section{Single-observation studies}

\subsection{Experiment design}

The sensitivity of analysis to the background error covariance and the observation error covariance can be tested through singleobservation experiments, e.g. conducting a full analysis but only assimilating one observation of interest. Background error covariance and observation error covariance are crucial components that determine the amplitude and structure of analysis increments, and control how the information content in observations is used to correct model forecasts. In the Goddard WRF-EDAS, the background error covariance is estimated from a finite number of ensemble WRF model forecasts. It obtains flow-dependent characteristics from up-to-date forecasts, but its accuracy is likely to be affected by under-sampling and systematic model errors. The observation error covariance is prescribed accounting for measurement error and representativeness error. In practice it needs to be tuned in balance with the background error covariance.

In early September 2010, an intense rainstorm hit southern France. In this storm, a maximum of $355 \mathrm{~mm}$ accumulated rainfall was recorded over a $48 \mathrm{~h}$ period. This storm event is selected for the single-observation studies in this section and the full data assimilation experiments in section 5 . It is characterized by three distinct phases. First, during the night from 6 to 7 September 2010, an oceanic cold front moved slowly across Europe and extended
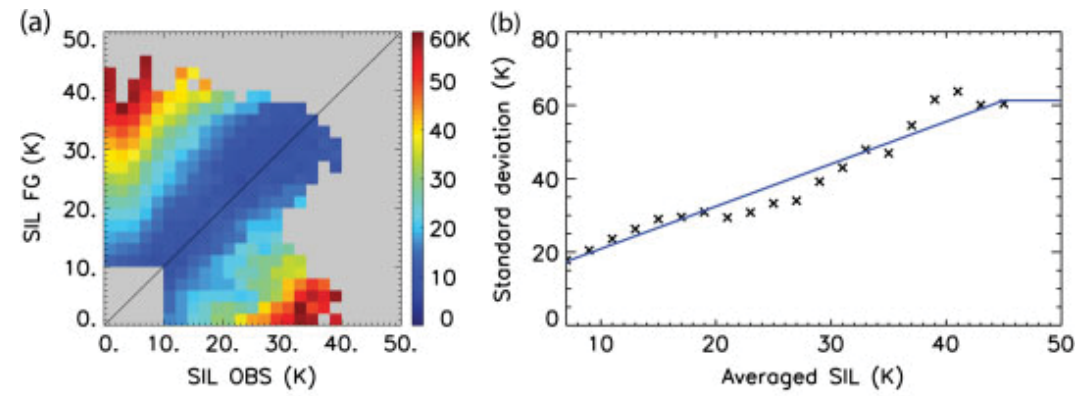

(c)

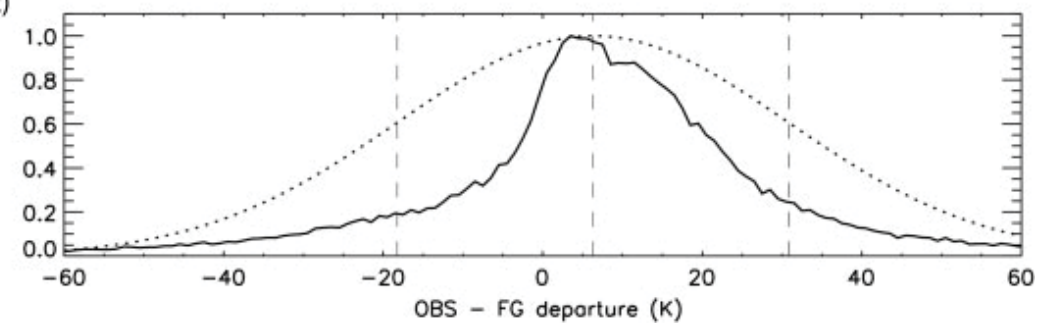

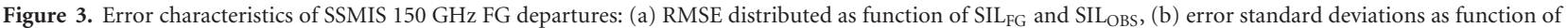
SIL $_{\mathrm{AVG}}$ in cross marks, and empirically fitted error model in blue line, and (c) PDF of FG departures in solid line as well as the reference Gaussian distribution in dotted line, with same mean and standard deviation as the PDF ( 6 and $25 \mathrm{~K}$ respectively). 
(a)

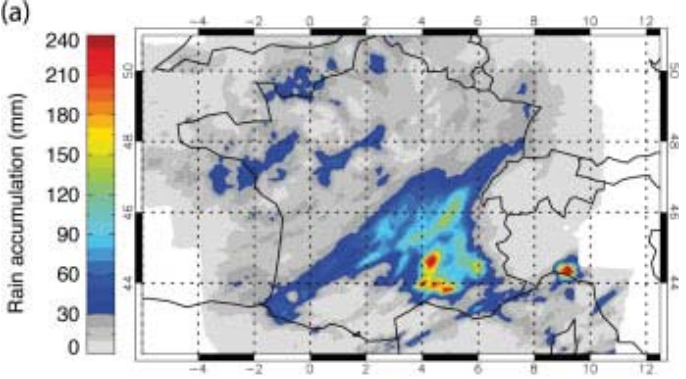

(b)
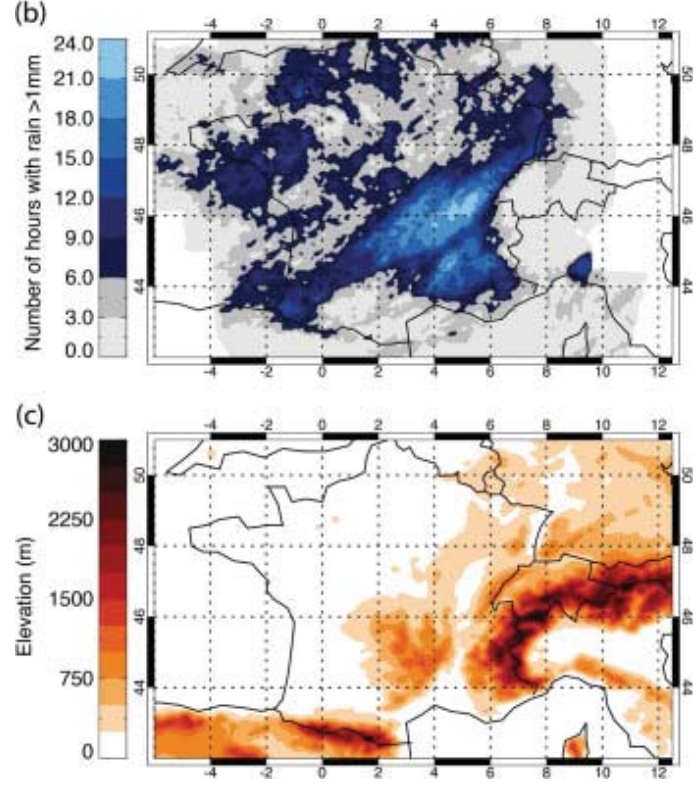

Figure 4. (a) Two-day rain accumulation from 1200 UTC 6 September 2010 to 1200 UTC 8 September 2010 at $9 \mathrm{~km}$ resolution estimated from surface radar measurements. (b) Number of hours during which $>1 \mathrm{~mm}$ of rain fell over the 2-day period as observed by surface radars. (c) Elevation map at $9 \mathrm{~km}$ resolution.

from northern Spain to Greenland. Due to its association with a moisture convergence from the Mediterranean Sea, storm activity was triggered, producing heavy precipitation over southern France. The second phase developed in the morning of the 7 th when the convective cells were transported by advection toward the Massif Central mountain region before aggregating into a stationary mesoscale convective system along the mountains. In the third phase during the night from 7 to 8 September 2010, storms moved eastward along the Mediterranean coastline toward Italy. As shown in Figure 4(a) and (b), the 2-day rain accumulation and the rainy hours recorded by surface radar illustrate the precipitation characteristics of the event. The cold front produced up to $100 \mathrm{~mm}$ of rain in the region of Lyon with persistent rain in a band from the southwest up to the northeast of France, with a maximum of more than $20 \mathrm{~h}$ of rain over the Rhône-Alpes region. The convective cells led to four rainfall maxima over southern France; in particular, a maximum of cumulated rain greater than $240 \mathrm{~mm}$ was produced in more than $18 \mathrm{~h}$ where the convective cells aggregated into a stationary mesoscale convective system.

Considering the flow-dependency of the background error covariance, two single-observation locations are selected within different precipitation systems both occurring at the analysis time of 0600 UTC 7 September 2010: case (a) is located in the cold front coming from the Atlantic Ocean and case (b) is located in a convective cell observed by the SSMIS instrument. In Figure 5, the observed locations for case (a) and case (b) are indicated by the white and black coloured crosses respectively. At location (a) the FG radiance at $91 \mathrm{~V}$ presents a stronger scattering signature than that of the observation. Case (a) has a positive FG departure. At location (b), a brightness temperature depression is observed but the convective cell is not present in the FG. Case (b) has negative FG departure. The analysis is expected to reduce precipitation in case (a), and to generate cloud and precipitation in case (b).

For each case, the following configurations are made to examine the analysis sensitivity to the ensemble-estimated background error covariance, the observation error standard deviations, and the different choice of MW channels:

(i) use SSMIS $91 \mathrm{~V}$ with observation error standard deviation of $25 \mathrm{~K}$, ensemble size of 32 members in estimation of background error covariance;

(ii) same as (i), but with ensemble size of 64 members;

(iii) same as (i), but with observation error standard deviation of $5 \mathrm{~K}$;

(iv) use SSMIS $183 \pm 7 \mathrm{GHz}$ with observation error standard deviation of $25 \mathrm{~K}$, ensemble size of 32 members.

For all configurations listed above, we start with the same forecasted background state, and examine (1) how much the assimilation of a single radiance observation reduces the FG departures, (2) how the analysis corrects hydrometeors produced by model physics, and (3) how the observation information is propagated into the precipitation forecast.

\subsection{The cold-front case with positive FG departure}

At the chosen location in the cold-front case, the FG is significantly lower than the observation ( $195.1 \mathrm{~K}$ vs. $259.7 \mathrm{~K}$ of $91 \mathrm{~V}$ ), indicating too much precipitation in the model forecast. As reported in Table 3, the positive FG departure is $64.6 \mathrm{~K}$. The black curves in Figure 6 depict vertical profiles of background hydrometeors (rain, snow, graupel, cloud water and cloud ice) corresponding to the FG at the observation location.

In configuration (i), the background error covariance calculated from an ensemble of 32 forecasts gives estimated error standard deviations in rain (noted $\sigma_{32}$ rain below) with a maximum around $0.2 \mathrm{~g} \mathrm{~kg}^{-1}$ as shown in Figure 6, the first row, represented by light grey shaded areas. After assimilating
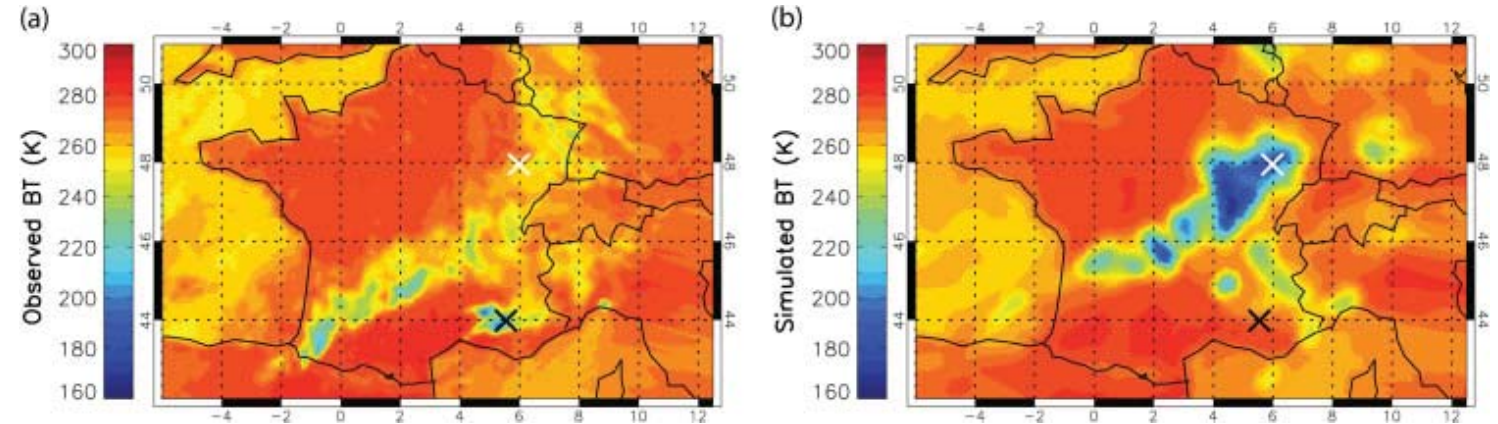

Figure 5. Brightness temperatures of $91 \mathrm{~V}$ at 0600 UTC 7 September 2010: (a) observed by the SSMIS instrument, and (b) simulated from a WRF forecast. The white crosses (respectively black crosses) correspond to the location of the cold-front single-observation case (respectively to the small-scale convective-cell single-observation case). 
Table 3. Departure and reduction on the departure after assimilating of a single observation with four configurations for the cold-front case with positive departure.

\begin{tabular}{|c|c|c|c|c|}
\hline Configuration: & $\begin{array}{l}\quad \text { (i) } \\
91 \mathrm{~V} / 25 \mathrm{~K} / \\
32 \text { ens. }\end{array}$ & $\begin{array}{l}\text { (ii) } \\
91 \mathrm{~V} / 25 \mathrm{~K} / \\
64 \text { ens. }\end{array}$ & $\begin{array}{l}\quad \text { (iii) } \\
91 \text { V/5 K/ } \\
32 \text { ens. }\end{array}$ & $\begin{array}{l}\quad \text { (iv) } \\
183 \pm 7 / 25 \mathrm{~K} / \\
32 \text { ens. }\end{array}$ \\
\hline Departure (K) & 64.6 & 64.6 & 64.6 & 58.8 \\
\hline $\begin{array}{l}\text { Reduction of the } \\
\text { departure }(\mathrm{K})\end{array}$ & 30.3 & 35.6 & 57.3 & 18.5 \\
\hline
\end{tabular}

the single observation at $91 \mathrm{~V}$ with a $25 \mathrm{~K}$ observation error, the brightness temperature of the analysis is $225.4 \mathrm{~K}$. This corresponds to a reduction of departure of $30.3 \mathrm{~K}$ reported in Table 4 . The blue curves in Figure 6 illustrate hydrometeors after analysis. The reduction of scattering signature in brightness temperature results in reduced rain, snow, ice and graupel, but increased cloud water. For instance, the increments on the rain profile are of approximately $-0.15 \mathrm{~g} \mathrm{~kg}^{-1}$ between model levels 1 and 10 , which is a reduction equivalent to $75 \%$ of $\sigma_{32}$ (rain).

The ensemble size is increased to 64 in configuration (ii) so that we can examine the under-sampling effect on the estimation of the background error covariance. In comparison with the results from configuration (i), the background error standard deviations of rain increase by $20 \%$ to around $0.24 \mathrm{~g} \mathrm{~kg}^{-1}$ (noted $\sigma_{64}$ (rain) below). The differences are illustrated in Figure 6(1a), with $\sigma_{32}\left(\right.$ rain) in light grey shade and $\sigma_{64}$ (rain) in dark grey. Similar changes are observed in the background error standard deviations for snow, cloud ice and graupel, shown in the first column of Figure 6, in grey shades. With a larger background uncertainty, the analysis gives more weight to the observation and produces a larger correction to microphysical variables. For example, as shown in Figure 6(1a), the analysis increments on the rain profile from configuration (ii) (red curve) reduce precipitation more than that of configuration (i) (blue curve). Consequently, the reduction of FG departure is greater in configuration (ii) than in configuration (i) at $35.6 \mathrm{~K}$ vs. $30.3 \mathrm{~K}$ (reported in Table 3 ). It should be noted there is very little background cloud water in this column (Figure 6(1e), black curve), and the increased ensemble size has negligible impact on the estimated background error standard deviations (grey shade). However, amplitudes of analysis increments are bigger than those in configuration (i), indicating a stronger error cross-covariance between cloud water and other hydrometeors in the larger ensemble estimation.

The observation error covariance represents the uncertainties in measurement, sampling and forward calculation. We use configuration (iii) to investigate the analysis sensitivity to different prescribed observation error standard deviations. The observation error standard deviation for the radiance data is set to $5 \mathrm{~K}$, in contrast with $25 \mathrm{~K}$ in configuration (i). The analysis draws the solution significantly closer to the observation when the observation error standard deviation is reduced. This configuration produces a reduction of FG departure of $57.3 \mathrm{~K}$ that is the largest reduction among all four configurations (Table 3). The result corresponds to large analysis increments that completely remove rain and snow (Figure 6(2a) and 6(2b)), reduce graupel by $50 \%$ (Figure $6(2 \mathrm{~d})$ ), as well as increase cloud water substantially (Figure 6(2e)). However, the amplitudes of corrections to microphysical variables are much bigger than background error standard deviations (Figure 6, second column, red curves vs. grey shades), implying the observation errors are underestimated and the observation is given too much weight for this particular situation.

Observations from different MW channels can impact analysis differently, because observations at various frequencies differ in their sensitivity to precipitation and other background variables. Configuration (iv) tests the analysis sensitivity to an observation from the $183 \pm 7 \mathrm{GHz}$ channel instead of the $91 \mathrm{~V}$, while the background error covariance and observation error standard deviations are kept the same as in configuration (i). At this frequency the FG departure is $58.8 \mathrm{~K}$ and the analysis produces a reduction of $18.5 \mathrm{~K}$ on the FG departure (Table 3 ). The analysis increments of hydrometeors are smaller than the counterpart in the assimilation of the $91 \mathrm{~V}$ channel. In order to have more direct comparison, we use the observation from the $91 \mathrm{~V}$ channel as 'passive monitoring' data, e.g. this observation is used to calculate departures only and is not assimilated in the analysis procedure. The passive monitoring of the $91 \mathrm{~V}$ channel in configuration (iv) shows a smaller reduction of the departure of $23.9 \mathrm{~K}$ when compared to $30.3 \mathrm{~K}$ in configuration (i). Hence the analysis has a lower sensitivity to the observation at $183 \pm 7 \mathrm{GHz}$ than $91 \mathrm{~V}$ with the same observation error standard deviations and background error covariance.

These results illustrate the capability of the Goddard WRFEDAS when the model forecast produces excessive precipitation and the MW radiance observation is used to identify a positive FG departure in brightness temperature. The ensemble forecasts have an adequate spread to provide background error covariance under precipitating conditions. The discrepancy between the simulated and observed brightness temperatures is effectively reduced and corresponding corrections to microphysical variables are applied through analysis. Doubling the ensemble size has a considerable impact on the background error covariance and the assimilation solution.

\subsection{The convective-cell case with negative FG departure}

The convective-cell case sets up a different scenario. Here the model fails to forecast the precipitation process that is observed by the single observation of SSMIS radiance and verified by the surface-based rainfall data. A large and negative FG departure of $-53.2 \mathrm{~K}$ is reported in Table 4. The black curves in Figure 7 depict vertical profiles of background hydrometeors corresponding to the FG at the single-observation location. There are very few precipitating hydrometeors in the background, in particular frozen precipitation. The small ensemble spread indicates that the observed convective precipitation is not represented in the ensemble. There is little sensitivity in the precipitation observation operator.

In configuration (i) with 32 ensemble members, the ensembleestimated background error standard deviations in rain are rather small with $0.02 \mathrm{~g} \mathrm{~kg}^{-1}$ at the maximum, as shown in Figure 7 , the first row, represented by light grey shaded areas. The estimated small background errors in rain directly result from the non-precipitating model background, not only in the central forecast but also in most of the ensemble members. The lack of signature of error growth in the convective rain region implies the initial condition is in the stable non-convective regime. The perturbations generated from the previous analysis error covariance could not produce an ensemble forecast spread that includes convective rain. After assimilating the single observation of SSMIS $91 \mathrm{~V}$ with the observation error standard deviation assigned at $25 \mathrm{~K}$, the FG departure is reduced by $8.9 \mathrm{~K}$ as reported in Table 4 . The analysis manages to increase the precipitating hydrometeors and clouds by a modest amount. For instance, the increments on rain profile are about $0.01 \mathrm{~g} \mathrm{~kg}^{-1}$, equivalent to $50 \%$ of $\sigma_{32}$ (rain).

The ensemble size is increased from 32 to 64 in configuration (ii) to examine if a larger ensemble size can help better estimate the background error covariance in a situation of non-precipitating model background. In contrast with the cold-front case where the ensemble spread is increased with a larger ensemble size, the error standard deviations in rain decrease by $25 \%$ when the ensemble size is increased in configuration (ii). The differences are illustrated in Figure $7(1 \mathrm{a})$, with $\sigma_{32}$ (rain) in light grey and $\sigma_{64}$ (rain) in dark grey. Similar results are observed in the background error standard deviations for snow, ice and cloud water, shown in the first column of Figure 7, in grey shades. 
(1)
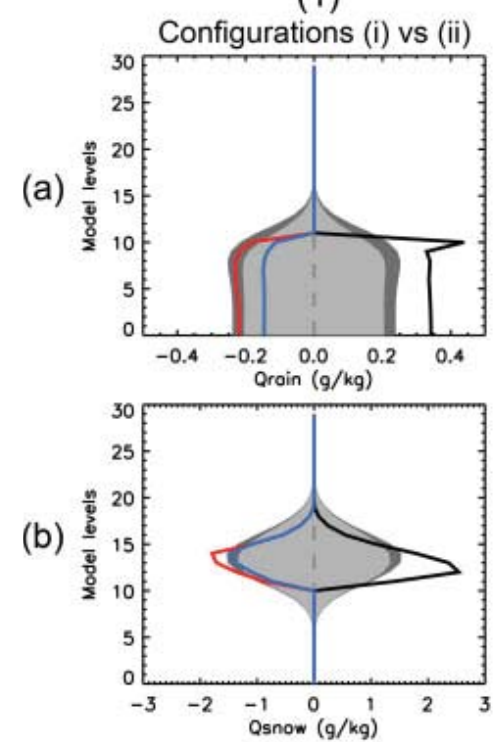

(c)

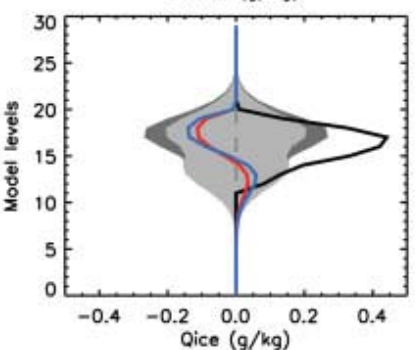

(d)

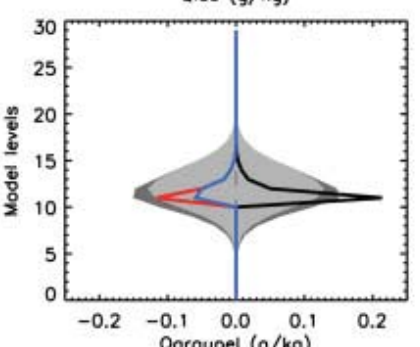

(e)

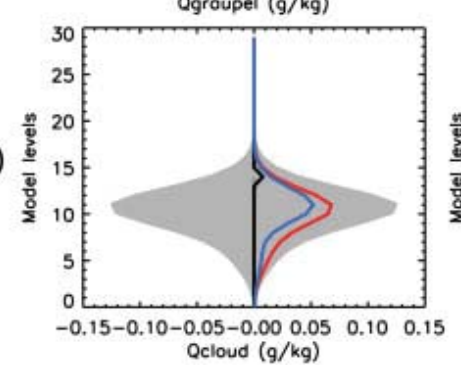

(2)
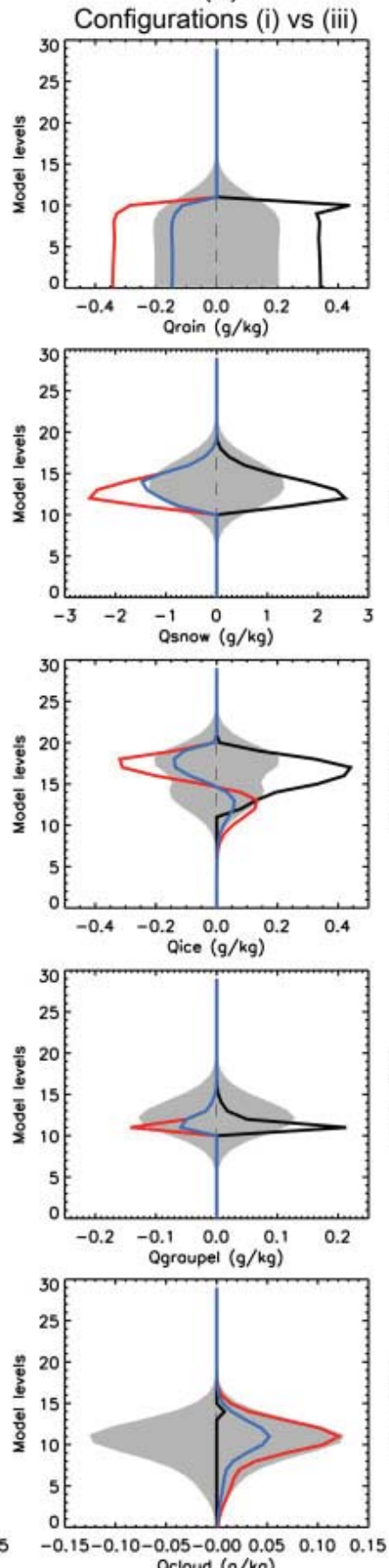

(3)
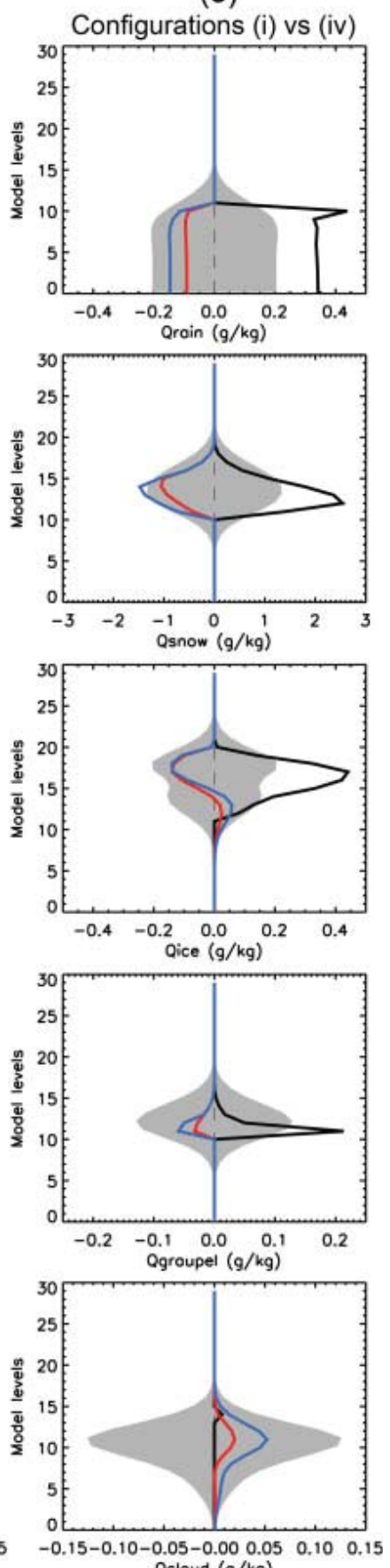

Figure 6. Row (a) to row (e) show background profiles (black lines) as well as increments (blue and red lines) of (a) rainwater, (b) snow, (c) ice, (d) graupel and (e) cloud water at the location of the cold-front single-observation case with positive FG departure. The light grey shaded areas represent corresponding vertical background error standard deviations. Column (1) shows the increments resulting from the single-observation assimilation in configuration (i) (blue lines) and in configuration (ii) (red lines); configuration (ii) leads to different background error standard deviations from configuration (i) and are represented by the dark grey shaded areas. Column (2) shows the increments resulting from the single-observation assimilation in configuration (i) (blue lines) and configuration (iii) (red curve). Both configurations have the same background error standard deviations so only light grey shaded areas are represented. Column (3) shows the increments resulting from the observation assimilation in configuration (i) (blue lines) and configuration (iv) (red lines). The background error standard deviations are the same as in column (2).

With a smaller background uncertainty, the analysis gives less weight to the observation and produces a smaller correction to microphysical variables. For example, as shown in Figure 7(1a) and $7(1 \mathrm{~b})$, the increments in the rain and snow profiles from configuration (ii) (red curve) increase both rain and snow less than those of (i) (blue curve). Consequently, the reduction of departure is smaller in configuration (ii) than in configuration (i), (3.9 K vs. $8.9 \mathrm{~K}$ as reported in Table 4). This experiment illustrates that a low probability of occurrence of convective rain limits the accuracy of ensemble-based estimation of background error covariance in hydrometeors because of a finite number of ensemble forecasts and model errors. The small spread around the non-precipitating background with a limited ensemble size also causes a lack of sensitivity in the ensemble representation of the perturbed precipitation observation operator.

Since the background error covariance in hydrometeors is likely to be small with the non-precipitating background, one possible route to increase the observational impact is to tune the observation error variance to a smaller value. In configuration (iii) the observation error standard deviations is prescribed to a 
Table 4. Same as Table 3 for the small-scale convective-cell case with negative departure.

\begin{tabular}{lcccc}
\hline Configuration: & (i) & \multicolumn{1}{c}{ (ii) } & (iii) & (iv) \\
& $91 \mathrm{~V} / 25 \mathrm{~K} /$ & $91 \mathrm{~V} / 25 \mathrm{~K} /$ & $91 \mathrm{~V} / 5 \mathrm{~K} /$ & $183 \pm 7 / 25$ \\
& 32 ens. & 64 ens. & 32 ens. & K/32 ens. \\
\hline $\begin{array}{l}\text { Departure } \\
\text { Reduction of }\end{array}$ & -53.2 & -53.2 & -53.2 & -40.8 \\
the departure & 8.9 & 3.9 & 27.7 & 0.8 \\
\hline
\end{tabular}

smaller value of $5 \mathrm{~K}$, while all the other settings remain the same as configuration (i). The analysis draws the solution significantly closer to the observation as seen in the cold-front case, achieving a reduction of $27.7 \mathrm{~K}$ to $\mathrm{FG}$ departure, as reported in Table 4. Figure $7(2 \mathrm{a})$ shows the analysis increments from configuration (iii) (red curve). Notice that the analysis increments in rain and snow are four times as big as the estimated background error standard deviations because of fitting the observation with an assigned small observation error standard deviation. The large analysis increments, beyond the expected range of the assumed Gaussian distribution, imply that the assimilation system is not able to use this observation to make an adjustment properly.

The analysis sensitivity to an observation from the $183 \pm 7 \mathrm{GHz}$ channel instead of $91 \mathrm{~V}$ is tested in configuration (iv). The observation impact is small compared to all other tests. At this frequency, the FG departure is $-40.8 \mathrm{~K}$ and the analysis only
(1)

(a)

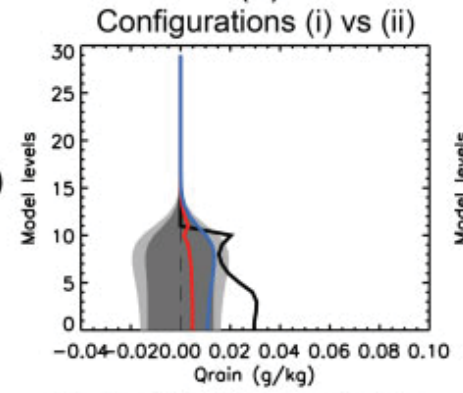

(b)

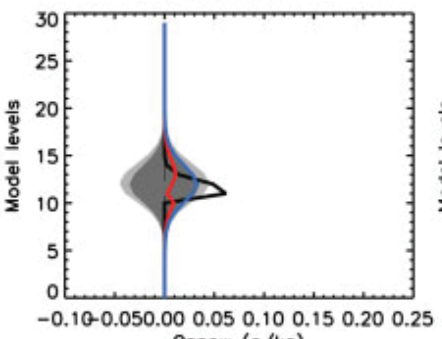

Qsnow ( $\mathrm{g} / \mathrm{kg}$ )

(c)

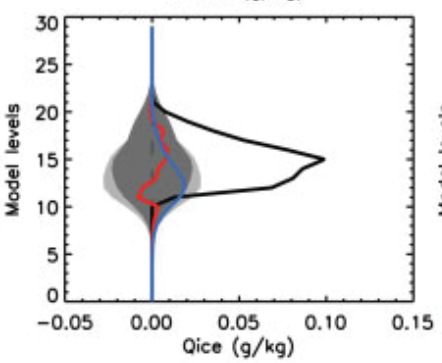

(d)

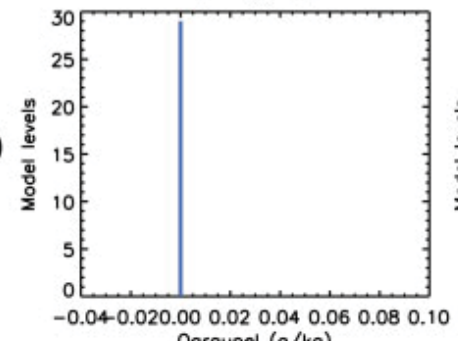

Qgroupel $(\mathrm{g} / \mathrm{kg})$

(e)

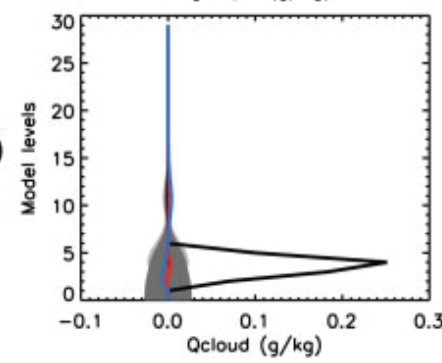

(2)

Configurations (i) vs (iii)
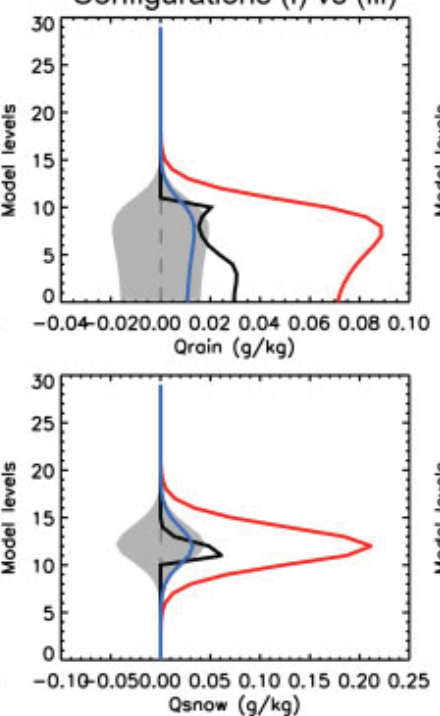

Qsnow $(\mathrm{g} / \mathrm{kg})$
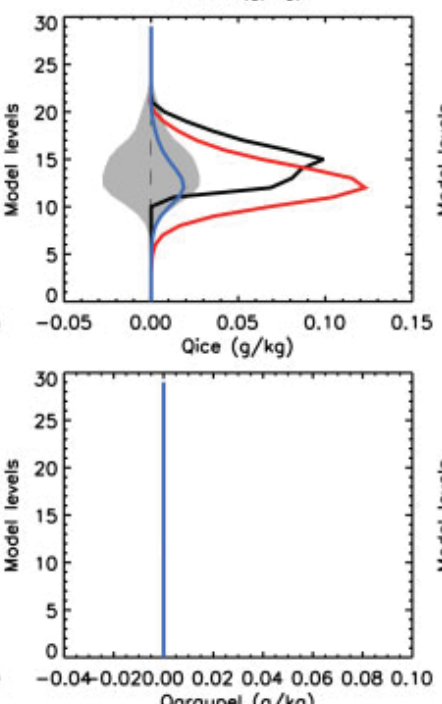

Qgroupel $(\mathrm{g} / \mathrm{kg}$ )

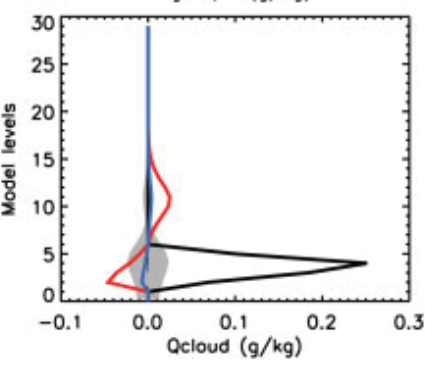

(3)

Configurations (i) vs (iv)
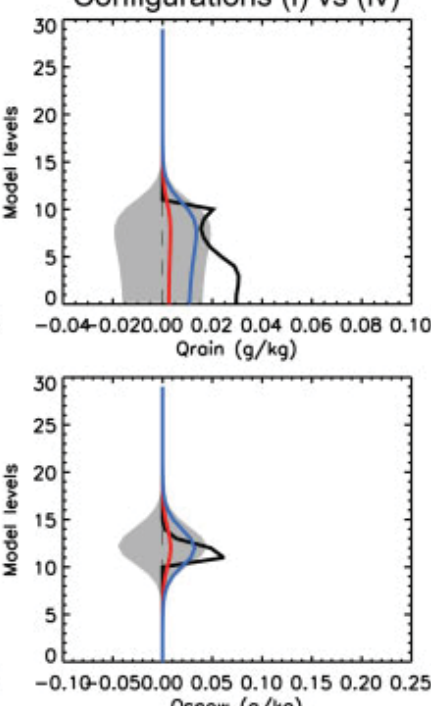

Qsnow ( $\mathrm{g} / \mathrm{kg}$ )
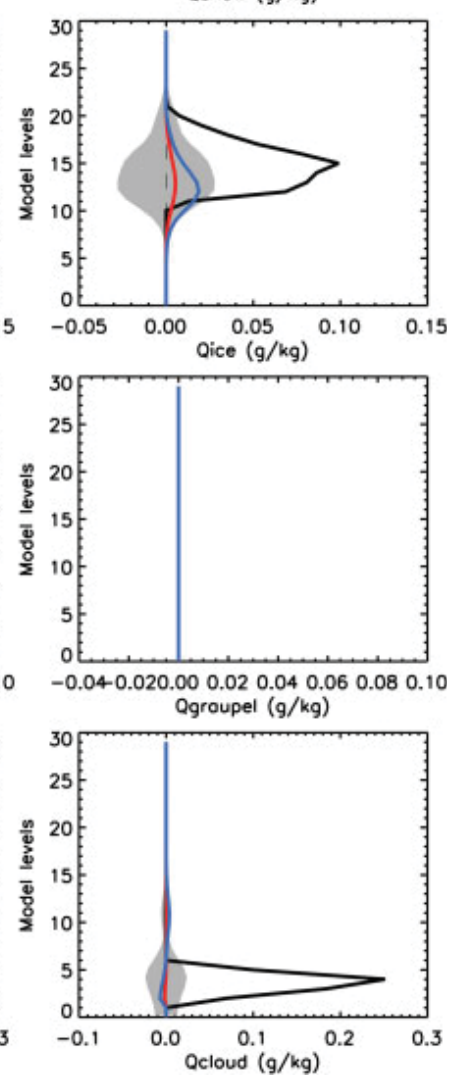

Figure 7. Same as Figure 6 but for the convective-cell single-observation case with negative FG departure. 
reduces the departure by $0.8 \mathrm{~K}$. Using the observation from channel $91 \mathrm{~V}$ as 'passive monitoring' data led to the same conclusion as above. Comparing the results of using $91 \mathrm{~V}$ and $183 \pm 7 \mathrm{GHz}$ observations, there is no obvious difference in the vertical structure of the analysis increments, suggesting that the vertical distribution of observation information is largely determined by vertical correlations in the background error covariance.

\subsection{Propagation of the observation information}

The precipitation information at one observed location is propagated to the surrendering area and to dynamic variables by the background error covariance. It is demonstrated by the spatial distributions of analysis increments from single-observation experiments as shown in Figure 8(a) and (b). The increments distribute heterogeneously in a geographical area of about $150 \mathrm{~km}$ diameter bounded by the localization scheme. In the cold-front case (Figure 8(a)), the local decrease of rainwater is associated with a dipole change of rainwater to the northeast of the observation location. These corrections on the background rainwater are also correlated with northeastward wind field increments (not shown). In the convective-cell case (Figure 8(b)), the positive rain increments are much weaker and stretched northward and southward from the observation location.

The model forecast provides temporal propagation of increments via interaction between dynamics and physical processes. As depicted in Figure 8(c) and (d), the forecast of accumulated surface precipitation is modified because of the correction to the forecast initial state with the single observation. In the cold-front case, the $3 \mathrm{~h}$ forecast shows a decrease of rain in an area surrounding the single-observation location in comparison to the control experiment (Figure $8(\mathrm{c})$ ). The dipole in the spatial distribution of rainwater increments and wind increments leads to an increase of accumulated rain northeast from the location of the single observation. A qualitative comparison to surface-based radar data confirms that the control experiment overestimates rainfall over a $500 \mathrm{~km}$ wide region in the vicinity of the singleobservation location and underestimates rainfall northeastward (Figure $8(\mathrm{e})$ ). Hence, the analysis correction based on information in the single observation at the forecast initial time makes a right correction to the $3 \mathrm{~h}$ precipitation forecast.

For the convective-cell case, the modification of the $3 \mathrm{~h}$ accumulated precipitation forecast due to the single observation is surprisingly significant considering the relatively small increments applied to the initial state. We see an increase in accumulated rain in an area northeastward from the single-observation location (Figure $8(\mathrm{~d})$ ). Comparing the control experiment to the radar data shows that this is the area where the control experiment underestimates rainfall. The positive rain increments are propagated northeastward through interaction with dynamics. The change to the forecasted rainfall is confirmed by the radar data.

The single-observation experiments illustrate the potential benefit of flow-dependent background error covariance to radiance assimilation under precipitating conditions. The findings also highlight the challenges that remain in ensemble estimation of background errors, such as non-precipitating background due to sampling errors and model errors. The accuracy of the background error estimation and the quality of the analyses are expected to improve when the data density increases. The impact with the data coverage from a pre-GPM constellation will be examined in the following sections.

\section{Data impact of a pre-GPM constellation}

Because precipitation varies widely in temporal and spatial scales and in underlying complex physical processes, to this day NWP models still have difficulty representing precipitation accurately in short-term forecasts and climate prediction. The rain event described in the previous section is used to evaluate the assimilation performance and assess the impact of pre-GPM constellation MW observations using the Goddard WRF-EDAS system. The MW observations from the instruments listed in Table 1 are used exclusively under precipitating conditions with symmetric decision (precipitation either detected by observations or indicated by forecast), except MHS for which all-sky data is included without scattering index screening. An observation outlier criterion is set at 2.5 times observation error standard deviations. In this case, any data with FG departure larger than the criterion will be rejected. All experiments assimilate conventional data as well as selected channels of Advanced Microwave Sounding Unit-A (AMSU-A) and High-resolution Infrared Sounder (HIRS) brightness temperatures under clear-sky conditions.

We configure four experiments, with the assimilation cycling period from 1200 UTC 6 September 2010 to 1200 UTC 8 September 2010:

(a) CNTL: The control experiment assimilating conventional observations including in situ measurements as well as radiance data from AMSU-A and HIRS selected under clear-sky conditions, with ensemble size of 32 members and $3 \mathrm{~h}$ assimilation cycles.

(b) EXP32-3H: The MW experiment assimilating all data as in CNTL and precipitation-affected radiances listed in Table 1, with ensemble size of 32 and $3 \mathrm{~h}$ assimilation window. The temporal sampling window for MW data is set to $1 \mathrm{~h}$ centred at the analysis time. Observation error standard deviation is prescribed at $25 \mathrm{~K}$.

(c) EXP64-3H: same as (b), but with ensemble size of 64 members.

(d) EXP32-1H: same as (b), but with $1 \mathrm{~h}$ assimilation window.

Analyses and forecasts from these experiments will be compared to examine: (i) the impact from adding MW precipitation-affected radiances (EXP32-3H vs. CNTL), (ii) the impact from increasing ensemble size for background error covariance estimation (EXP64-3H vs. EXP32-3H), and (iii) the impact from using a shorter analysis interval to increase MW data temporal coverage (EXP32-1H vs. EXP32-3H).

A statistically robust impact assessment of the bias correction scheme, detailed in section 3.2.1, would require an investigation involving a longer assimilation period. Nevertheless, short-term assimilation experiments (with and without bias correction) indicate a positive impact on 2-day accumulated rainfall forecast for this particular event (3.5\% improvement of the root-meansquare error (RMSE) and $1.3 \%$ of the bias with respect to surface radar data). Hence, the bias correction is applied to SSMIS radiances in the EXP32-3H, EXP64-3H and EXP32-1H experiments.

Precipitation forecasts from all experiments listed above are verified against an independent surface-based rainfall product. This surface rain estimate is retrieved from the French operational 'Application Radar à la Météorologie Infra-Synoptique' (ARAMIS) radar network and adjusted hourly with rain-gauge data (Tabary, 2007). The dataset has $1 \mathrm{~km}$ spatial resolution and $5 \mathrm{~min}$ temporal resolution, which is averaged to $9 \mathrm{~km}$ resolution and accumulated over analysis and forecast intervals accordingly. In this study the radar rain estimates are treated as the ground truth. Nevertheless, Tabary et al.(2007) reported that the ARAMIS rain product is characterized by errors depending on the distance from the radar locations prior to rain-gauge adjustment. In future applications when an error bar is provided with the basic rain amount in radar-based rain products (e.g. Kirstetter et al., 2010), errors can be taken into account in the verification process (e.g. Roca et al., 2010; Chambon et al., 2012).

\subsection{System performance}

The Goddard WRF-EDAS uses ensemble forecasts to estimate the background error covariance, and applies the maximum 

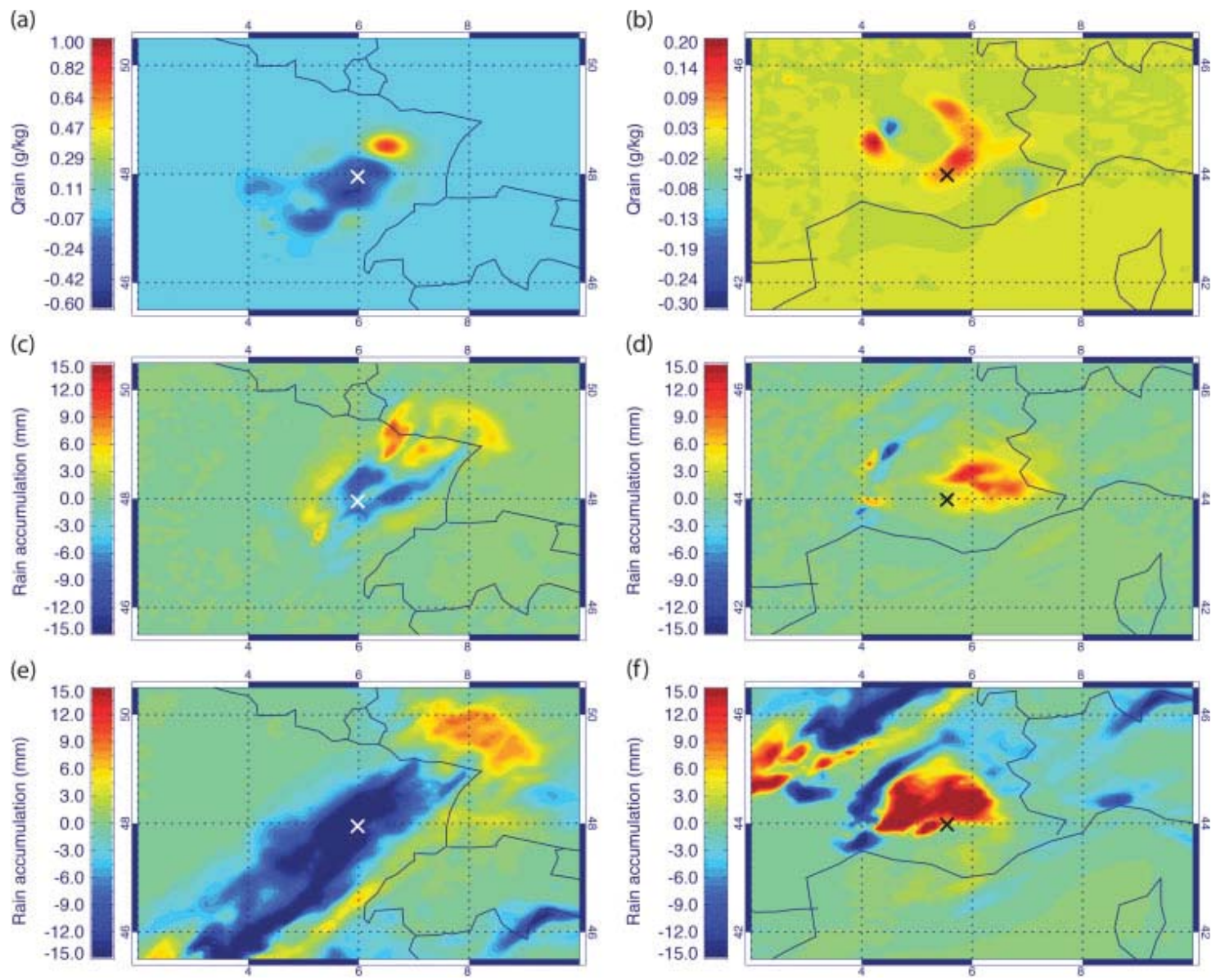

Figure 8. Increments on rainwater at $700 \mathrm{hPa}$ after assimilating single observation of $91 \mathrm{~V}$ for (a) the cold-front case and (b) the convective-cell case single-observation locations at 0600 UTC 7 September 2010, using $5 \mathrm{~K}$ as the observation error standard deviation. (c), (d) Difference between the following $3 \mathrm{~h}$ rain accumulation forecast (0600 and 0900 UTC) with and without assimilation of the single observations. (e), (f) Difference between the following $3 \mathrm{~h}$ rain accumulation from surface radar estimations and $3 \mathrm{~h}$ rain accumulation forecast without assimilation of the single observation. The colour scale is kept the same for the second and the third row; differences larger than the range displayed are represented in dark blue and dark red in the third row.

likelihood ensemble square root filter (MLEF) scheme to update the analysis ensemble covariance. It is critical particularly for precipitation data assimilation that the background error covariance adequately represents the forecast error growth in the precipitating region. The analysis quality relies on the system's capability to maintain a sufficient spread of the ensemble with a limited ensemble size.

Figure 9 depicts the PDF quartiles of the normalized background error standard deviations of rainwater in precipitating regions during the 2-day assimilation cycling period. The background error standard deviations (the diagonal of error covariance) are normalized by the local background rainwater content and collected in the entire domain to form the distribution. For EXP32-3H, in which MW observations are assimilated using 32 ensemble members (Figure 9(a)), the PDF mean fluctuates between 60 and 100\% normalized error standard deviations, the lower quartile (respectively higher quartile) between 20 and 50\% (respectively from 60 to $130 \%$ ). This indicates that the system sustains an adequate spread of the ensemble in terms of rainwater during the cycling period of the case-study. When the ensemble size is increased to 64 in EXP64-3H (Figure 9(b)), the impact on the spread is noticeable as indicated by the PDF mean and quartiles of larger background error standard deviations. The $1 \mathrm{~h}$ assimilation window in EXP32-1H (Figure 9(c)) limits the amplitude of forecast error growth due to relatively shorter forecast model integration time. The background error standard deviations are smaller in comparison to the counterparts in the other two experiments with a $3 \mathrm{~h}$ analysis window. Nonetheless, a spread of the ensemble is sustained throughout the 2-day period with PDF mean maintained between 50 and $80 \%$.
As demonstrated in Zhang et al.(2013) and in the single-observation experiments described in section 3 , the flow-dependent background error covariance of the Goddard WRF-EDAS system is characterized by background errors significantly larger in model-predicted cloudy and precipitating regions. This implies that the analysis process will give relatively more weight to observations in FG storm regions. On the other hand, the background errors for hydrometeors may be underestimated in FG cloud-free regions due to lack of sensitivity to perturbations under such conditions. Discrepancies in the intensity and location of precipitation between observation and FG can be categorized as positive FG departures and negative FG departures according to the two situations described above. Once the categorization is established, the effectiveness of error reduction by analysis can be deciphered accordingly. Figure 10(b) shows the RMSE of total precipitation-affected radiance FG departures and analysis departures, categorized by positive FG departures (red) and negative FG departures (blue). For analysis using MW observations, the RMSE reduction is consistently larger in the positive FG departure category than in the negative FG departure category. For instance at 0600 UTC 7 September 2010, the RMSE in radiance is decreased by $15 \mathrm{~K}$ in the areas where background produces excessive precipitation (positive FG departures) but only $5 \mathrm{~K}$ in the areas where background fails to produce precipitation observed by MW data (negative FG departures). This illustrates both an advantage and a limitation of a flow-dependent background error covariance estimated from ensemble forecasts for cloud and precipitation data assimilation. The advantage is that the flow-dependency enhances the capability of the data assimilation system to make corrections if ensemble forecasts 

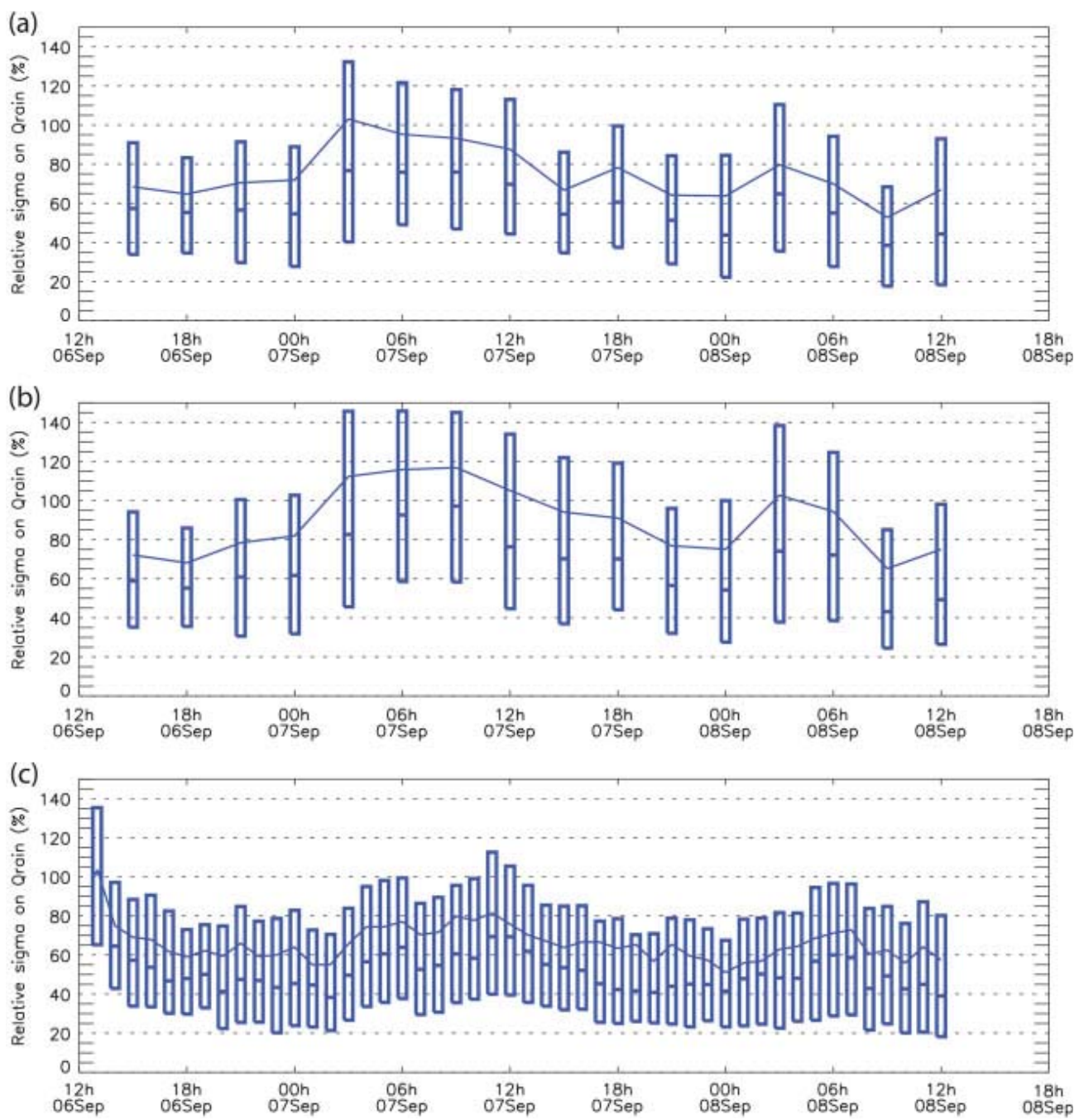

Figure 9. Time series of the $25 \%$, median and $75 \%$ quartiles of the rainwater normalized error standard deviation PDFs (including only rainwater samples greater than $0.1 \mathrm{~g} \mathrm{~kg}^{-1}$ ), for (a) EXP32-3H with 32 ensemble members and $3 \mathrm{~h}$ analysis window, (b) EXP64-3H with 64 ensemble members, and (c) EXP32-1H with 32 ensemble and $1 \mathrm{~h}$ analysis window. This figure is available in colour online at wileyonlinelibrary.com/journal/qj

predict cloud and precipitation in the background. The disadvantage is that it will not be effective where forecasts erroneously predict a cloud-free or non-precipitating condition.

\subsection{MW data impact on precipitation forecasts}

The analysis increments produced by assimilating MW radiance are applied to the WRF state variables and the data impact on precipitation forecasts is shown in terms of domain mean of surface rainfall for the CNTL and EXP32-3H experiments in Figure 10(a). The surface radar rainfall product serves as the verification. The control experiment captures the double peak of mean rainfall in the time series as observed by the radars with a $3 \mathrm{~h}$ phase error. The assimilation of MW data makes the precipitation forecasts produce a rainfall mean closer to the verification, though by a modest amount. Looking at the synoptic features of precipitation in the cold-front region and the convective-cell area, we notice that during the first two phases the model overestimates the rain when the cold front crosses western Europe, and fails to generate the convective cells southward as well as the associated heavy precipitation. Hence, the analysis correctly decreases rainfall of the predicted cold-front region, but does little to correct the too- low precipitation in the observed convective-cell area. In the third phase of the event, the model forecast produces rain cells moving eastward in general agreement with observations. The increase of mean rain during the third phase of the storm exemplifies the system's capability to increase rain where FG and observations in radiances both exhibit scattering signals.

The assimilation of MW data from a constellation of satellites ultimately impacts the accuracy of model accumulated precipitation forecasts over the 2-day period. Figure 11 shows the 2-day accumulated rain forecasts from the four experiments as well as their differences compared to the radar verification data (shown previously in Figure 4(a)). The dominant maximum of the storm indicated by the verification data at $\left(4.5^{\circ} \mathrm{E}\right.$, $\left.44.8^{\circ} \mathrm{N}\right)$ is reproduced in the control forecast $(\mathrm{CNTL})$ with a slight northward misplacement. The associated difference map (Figure 11(b)) indicates that the CNTL forecast has overestimated precipitation along the cold-front line of roughly $200 \mathrm{~km}$. It has also missed rainfall where convective cells produced heavy rain. Overall in the storm domain the CNTL forecast has a positive bias of $3.2 \mathrm{~mm}$ and an RMSE of $30.8 \mathrm{~mm}$, as reported in Table 5.

EXP32-3H has assimilated the constellation of MW data. The verification for the EXP32-3H forecast gives evidence of a positive data impact. The rain forecast is improved over the line of the cold front mentioned above. However, where ensemble forecasts fail to produce the heavy precipitation associated with convective cells, the assimilation of MW observations has very little impact on inducing convective rain in the subsequent forecasts. Overall the RMSE is reduced to $28 \mathrm{~mm}$, corresponding to an improvement of $8.1 \%$ against the experiment CNTL. As reported in Table 5, the 

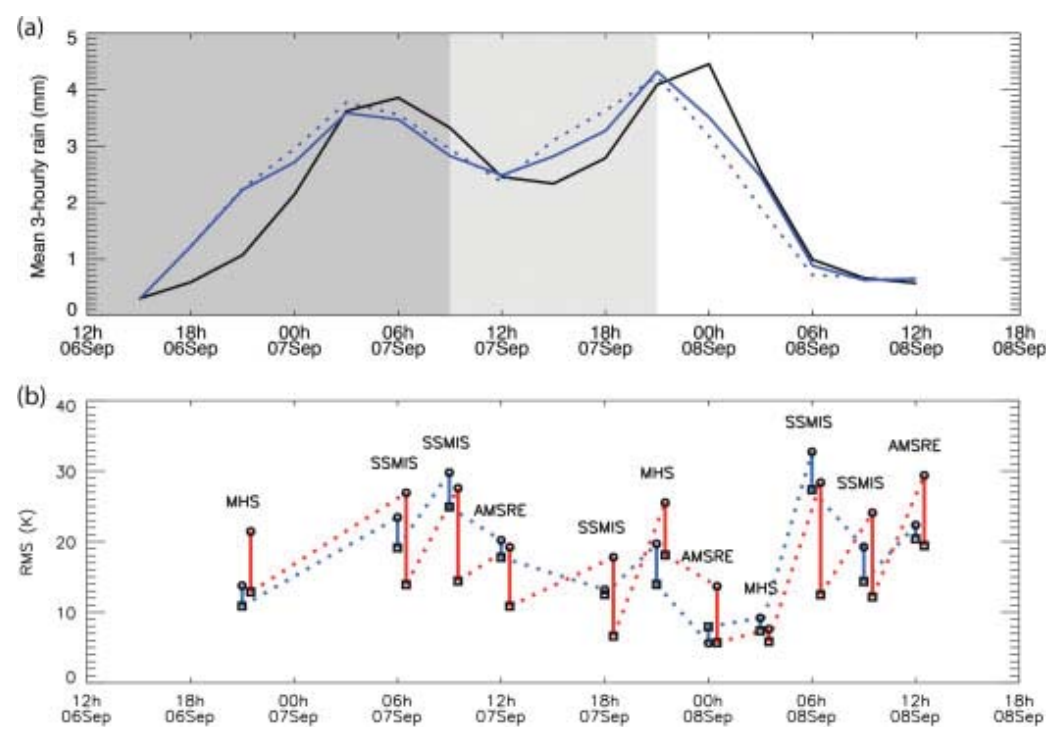

Figure 10. (a) Time series of mean 3-hourly rain over the domain $\left(5^{\circ} \mathrm{W}-7.5^{\circ} \mathrm{E}, 42.5-51^{\circ} \mathrm{N}\right)$. The black line corresponds to surface radar rain estimates; the dashed blue line corresponds to the CNTL experiment and the full blue line to EXP32-3H assimilating SSMIS, AMSR-E and MHS MW observations. The dark grey, light grey and white backgrounds show the three distinct phases of the meteorological event. (b) Time series of RMSE of FG departures and RMSE of analysis departures of SSMIS MHS and AMSRE at $91 \mathrm{~V}, 91 \mathrm{GHz}$ and $89 \mathrm{~V}$ respectively. The red curve (respectively blue curve) corresponds to the reduction of RMSE for samples with positive departures (respectively negative departures). Circles show the RMSE of FG departures and squares show the RMSE of analysis departures.

Table 5. Statistics of comparisons between 2 days accumulated rainfall of radar-based rainfall estimates and WRF model forecasts from four assimilation experiments, sampled over land at $9 \mathrm{~km}$ resolution, in the domain $\left(5^{\circ} \mathrm{W}-7.5^{\circ} \mathrm{E}\right.$, $\left.42.5-48^{\circ} \mathrm{N}\right)$.

\begin{tabular}{lccc}
\hline Experiments & $\begin{array}{l}\text { Bias }(\mathrm{mm}) \text {; relative } \\
\text { bias }(\%)\end{array}$ & Correlation & $\begin{array}{l}\text { Root-mean-square } \\
\text { error }(\mathrm{mm}) ; \text { relative } \\
\text { RMSE (\%) }\end{array}$ \\
\hline CNTL & $3.2 \mathrm{~mm} ; 9.2 \%$ & 0.57 & $30.8 \mathrm{~mm} ; 88.8 \%$ \\
EXP32-3H & $2.9 \mathrm{~mm} ; 8.4 \%$ & 0.63 & $28.0 \mathrm{~mm} ; 80.7 \%$ \\
EXP64-3H & $3.4 \mathrm{~mm} ; 9.8 \%$ & 0.59 & $30.6 \mathrm{~mm} ; 88.2 \%$ \\
EXP32-1H & $2.7 \mathrm{~mm} ; 7.8 \%$ & 0.61 & $27.6 \mathrm{~mm} ; 79.5 \%$ \\
\hline
\end{tabular}

Sample size: 4845

bias is reduced slightly, and the correlation is increased to $0.63 \mathrm{vs.}$ 0.57 of CNTL.

With a larger ensemble size, EXP64-3H is expected to extract information from MW data more effectively and to have a larger impact on rainfall forecasts. However, the results from EXP64-3H do not show an improvement over EXP32-3H forecasts in terms of bias and RMSEs in precipitation forecasts. The difference map in Figure 11(f) shows that the overestimation of rainfall along the cold-front line is not reduced and the rainfall in the convectivecell region remains underestimated. Statistically the background error covariance estimated by more ensemble members should have larger error standard deviations and less noisy correlations, as indicated by the single-observation experiments in section 4 . However, its impact on the subsequent precipitation forecast skills is complicated by many factors including how error crosscovariance is changed between hydrometeors and other variables, and how nonlinear model physics responds to the analysis correction. In this particular case-study, we observed that the structures of analysis increments are different between EXP64$3 \mathrm{H}$ and EXP32-3H, mainly controlled by their corresponding error covariance, since the same observation error covariance and same observations are used in both experiments. The increment spatial distribution has finer-scale structures in EXP64-3H, which may interact with model physics in a nonlinear and complex manner in the heavy rain region during the model forecast. In both experiments the localization scale is kept the same, which may need tuning to better trade off sampling error and scaled imbalance (Mitchell et al., 2002). It is possible that the forecast in EXP64-3H has a less coherent response to the analysis increments with more localized structure. Hence, in the larger area the overestimation of precipitation is not corrected as much as that in EXP32-3H. On the other hand, how to adjust prescribed observation error covariance to ensure appropriate balance on weighting of forecast and observations is still an unresolved issue.

A constellation of satellites like the GPM constellation with high data occurrence has a great potential to provide information for the model physics through data assimilation. The experiment EXP32-1H prototypes a rapid update cycle configuration that might be used for nowcasting or re-analysis purposes. In the other experiments the $3 \mathrm{~h}$ assimilation cycles only make use of MW data that fall into the $1 \mathrm{~h}$ sampling window centred at the analysis time. For example, as illustrated in Figure 1, with the observing system available in 2010,3-5 observations per day per location are used with the $3 \mathrm{~h}$ assimilation cycles configuration instead of more than 12 available during a day in the midlatitudes (Figure 1(a)). It should be noted that in the future GPM-era, out of 19 observations available per day, per location, only 6 observations would be used in the system with a $3 \mathrm{~h}$ analysis window (Figure 1(b)). To increase the data temporal coverage, EXP32-1H carries out analysis at every hour and uses all available MW data because there is no time gap between data sampling for analysis. EXP32- $1 \mathrm{H}$ forecasts demonstrate the most improvement in areas with overestimated rainfall among all experiments, as shown in Figure 11(h). Forecast error statistics, as reported in Table 5, confirms the larger positive data impact contributed from the increased temporal data coverage: RMSE is the lowest at $27.6 \mathrm{~mm}$ corresponding to an improvement of $9.2 \%$ of the RMSE over that of CNTL.

The results of the four experiments show the sensitivity of model precipitation forecasts to the assimilation of precipitationaffected MW observations within the Goddard WRF-EDAS system. The improvement related to using information in precipitation-affected radiances is noticeable and promising. More frequent data coverage as anticipated in the GPM constellation will have a positive impact on precipitation forecasts. This is clearly demonstrated by the experiment with a $1 \mathrm{~h}$ assimilation window. The verification and comparisons of these experiments also highlight remaining issues, such as the intricate balance between the background error covariance and observation error covariance, as well as the lack of sensitivity in misplaced nonprecipitating background. For instance, the background error covariance in EXP64-3H has a larger error magnitude as shown 
(a)

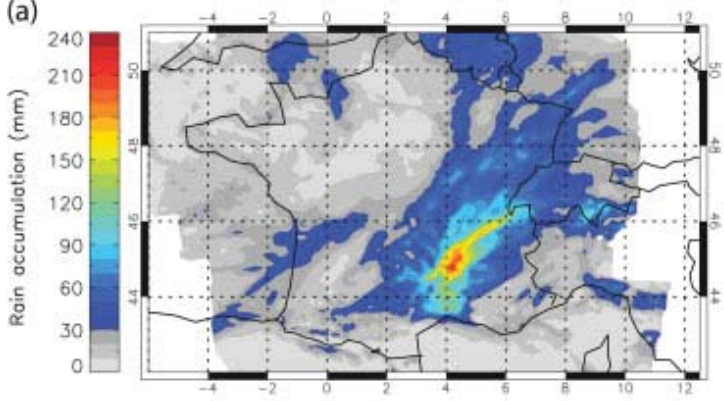

(c)

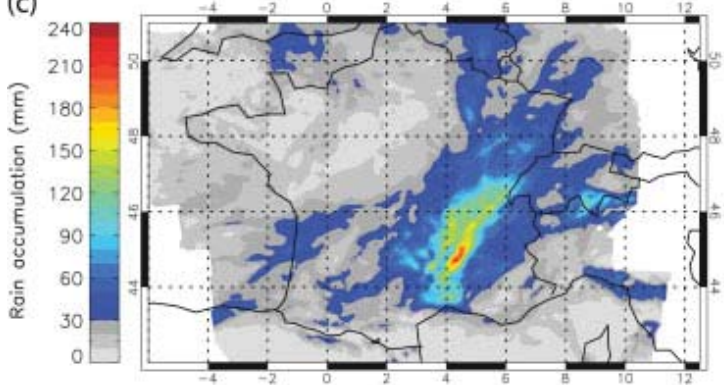

(e)

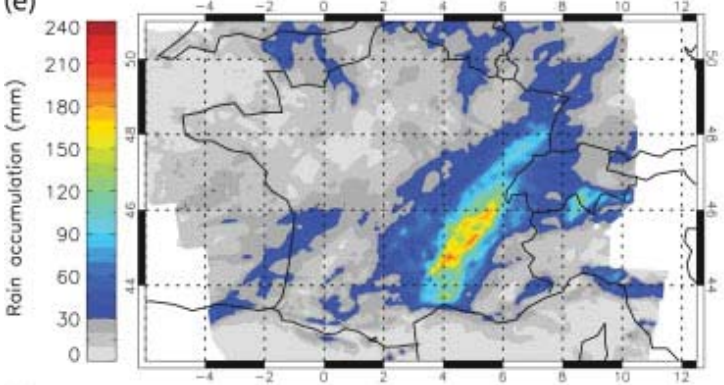

(g)

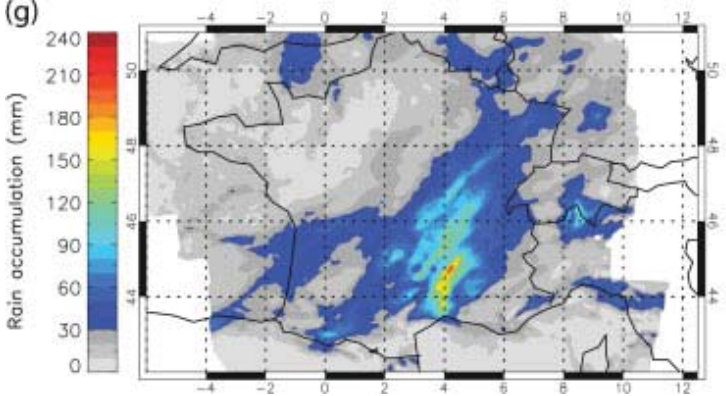

(b)

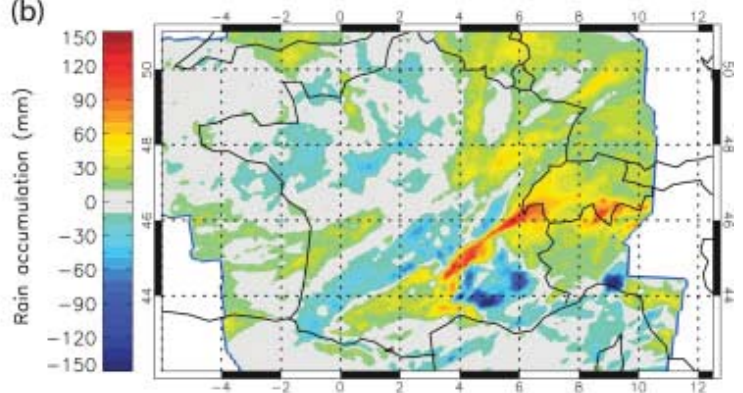

(d)

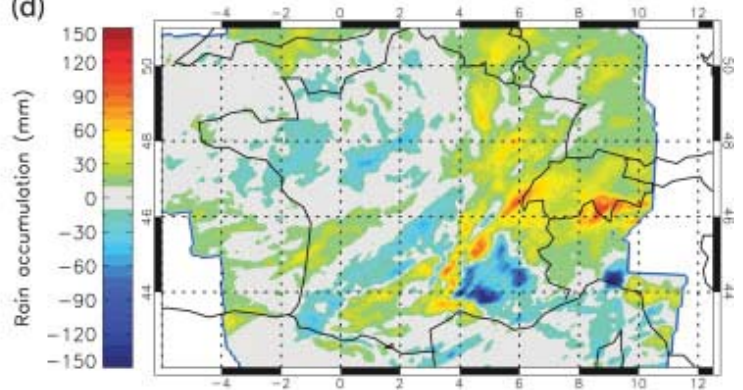

(f)

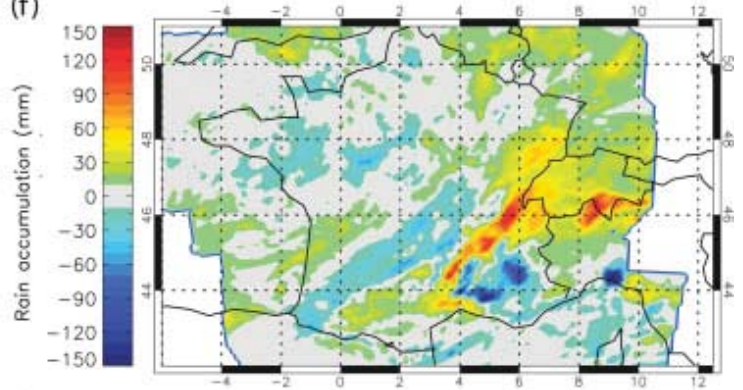

(h)

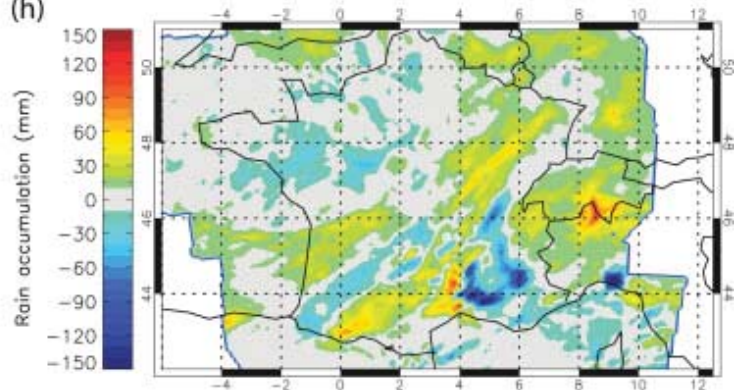

Figure 11. Two-day rain accumulation of WRF model forecasts from four experiments (left column) and the corresponding difference maps between forecasts and verification radar surface rain estimates (right column), from 1200 UTC 6 September 2010 to 1200 UTC 8 September 2010 at 9 km resolution. First row ((a) and (b)): CNTL. Second row ((c) and (d)): EXP32-3H. Third row ((e) and (f)): EXP64-3H. Last row ((g) and (h)): EXP32-1H.

in Figure 9(b), but the observation error standard deviation is fixed as that in EXP32-3H. The resulting analysis could be less balanced in relative weighting. The results presented here suggest that prescribing observation errors in precipitating regions may require a more situation-adaptive approach particularly when the background error covariance is flow-dependent. As another example, the ensemble forecasts systematically fail to predict precipitation of convective cells. This lack of sensitivity in precipitation in the area resulted in negligible background error growth locally and prevented analysis from drawing information from observations.

\section{Summary and discussion}

The data impact of satellite precipitation observations on the accuracy of numerical weather prediction is largely affected by the characterization of background and observation errors and the representation of nonlinear cloud/precipitation physics. The Goddard WRF-EDAS has been developed to assimilate satellite precipitation observations with flow-dependent background error covariance, nonlinear microphysics and an all-sky radiative transfer model as the observation operator. A series of assimilation experiments are carried out using precipitation data from a pre-GPM constellation in a WRF model domain of $9 \mathrm{~km}$ resolution in western Europe. The key objectives are to examine the analysis sensitivities to observation errors and background error covariance, and to assess the data impact on mesoscale quantitative precipitation forecasts.

An empirical bias correction for precipitation-affected MW radiances is developed based on the statistical analysis of SSMIS data collected from precipitation events in an 8-month period. A symmetric Scattering Index over Land is chosen as the predictor. The bias correction model parameters are calculated using only FG departure samples where observations and FG agree on precipitating conditions. The bias correction removes biases in observations caused by systematic errors of RTM and measurements, and avoids the contamination by the occurrence bias of scattering due to excessive ice-phase precipitation in the 
background state. The bias correction is applied to precipitationaffected radiance FG departures before the analysis step in assimilation cycling. Short-term assimilation experiments with and without bias correction indicate a positive impact on 2-day accumulated rainfall forecast for this particular event (3.5\% reduction of the RMSE and $1.3 \%$ of the bias verified against the surface radar data). The current data assimilation and radiance bias correction schemes are not designed to correct systematic model bias. Nevertheless, precipitationaffected radiance assimilation can diagnose systematic model errors in microphysics such as excessive precipitating ice content, and the relevant statistical information can feed through to model physics improvement and tuning.

Background error statistics play a critical role in how the analysis interprets and propagates observation information into forecasts. The single-observation experiments demonstrated the potential benefit of flow-dependent background error covariance to radiance assimilation under precipitating conditions. The analysis increments in hydrometeors are distributed heterogeneously reflecting the storm structure. The background error crosscovariance provides a link between dynamical and microphysical variables and results in a positive correction to precipitation forecasts, as verified by the radar-based surface rain estimate.

The data impact is assessed by data assimilation cycling experiments on a storm event that occurred in France in September 2010. Results show that the assimilation of MW precipitation observations from a satellite constellation mimicking GPM has a positive impact on the accumulated rain forecasts verified with surface-radar rain estimates. The experiment with a $1 \mathrm{~h}$ assimilation window increases the temporal data coverage as anticipated in the GPM constellation. Considering the fast evolution of storm structure and location, rapid-update assimilation allows the analysis to be more frequently constrained by observations and to a better forecast with smaller root-mean-square errors compared to that of $3 \mathrm{~h}$ analysis interval experiments.

The data impact studies also expose unresolved issues on how to most effectively utilize precipitation observations in NWP data assimilation. The ensemble approach of the Goddard WRF-EDAS is advantageous in providing flow-dependency to background error covariance; on the other hand it is also vulnerable to the reduced-rank sampling errors and systematic model errors in clouds and precipitation. For instance, in both singleobservation experiments and full data assimilation experiments, the ensemble-estimated background error standard deviations of hydrometeors are negligible in the convective-storm region with non-precipitating background but precipitating observations. In this situation of a low probability of occurrence of convective rain, the lack of ensemble spread results in a small background uncertainty. Therefore observations have very little impact on analysis and precipitation forecasts. In the data assimilation system with model errors such as unresolved convective-scale rain or displacement of precipitation, representative errors are accounted for as part of observation errors. Future development will incorporate approaches that include a hybrid variationalensemble method for background error estimation (Zhang and Zhang, 2012) and ensemble estimation with displacement error correction (Aonashi and Eito, 2011).

It remains a challenge to characterize observation errors under precipitation conditions. The off-line bias correction scheme relies on empirically estimated parameters from past FG radiance departures. The uncertainties in the modelling of scattering and land emissivity are critical factors for radiance assimilation over land surface (Baordo et al., 2012). These factors need to be further investigated and accounted for in the bias correction and observation error model. The development is under way to replace the Mie sphere approximation with a non-sphere ice particle database for ice-phased precipitation in RTM. The icephased particle distribution parameters, such as the intercept and the density, will also be re-evaluated in model cloud physics and in RTM. Further work will be directed towards identifying sources of biases and precipitation-related predictors. To effectively discriminate and attribute bias to its source likely requires an adaptive correction scheme that allows the bias estimation to be constrained by relevant ancillary data. In the reality of possible local underestimation or overestimation of flow-dependent background error covariance in the presence of systematic model errors in hydrometeors, an adaptive tuning of observation error variance (Talagrand, 1999; Desroziers and Ivanov, 2001) may also be considered to maintain the balance of analysis weighting.

\section{Acknowledgements}

The authors thank Wesley Berg at Colorado State University for providing the SSMIS FCDR inter-calibrated brightness temperature dataset, and Météo-France and HyMex database teams (ESPRI/IPSL, SEDOO/OMP) for providing the surface rainfall product from the ARAMIS radar network. Jean-Francois Mahfouf and Chris Kidd are acknowledged for their helpful remarks. Jan Angevine is recognized for editing the manuscript. The authors are grateful to two anonymous reviewers for their insightful and constructive comments that improved the article. This research is supported by the Global precipitation Measurement (GPM) Flight Project at NASA Goddard Space Flight Center and the French Ministry of the environment. Computations were performed at NASA Advanced Supercomputing (NAS).

\section{References}

Aonashi K, Eito H. 2011. Displaced ensemble variational assimilation method to incorporate microwave imager brightness temperatures into a cloudresolving model. J. Meteorol. Soc. Jpn. 89: 175-194, DOI: 10.2151/jmsj.2011301

Auligné T, McNally AP, Dee DP. 2007. Adaptive bias correction for satellite data in a numerical weather prediction system. Q. J. R. Meteorol. Soc. 133 . 631-642, DOI: 10.1002/qj.56.

Baordo F, Geer AJ, English S. 2012. 'SSMI/S radiances over land in the all-sky framework: One year report', Report No. 27. EUMETSAT/ECMWF Fellowship Programme Research: 35 pp. http://www.ecmwf.int/publications. [Accessed on 9 September 2013].

Bauer P, Geer AJ, Lopez P, Salmond D. 2010. Direct 4D-Var assimilation of all-sky radiances. Part I: Implementation. Q. J. R. Meteorol. Soc. 136: 1868-1885, DOI: 10.1002/qj.659.

Bauer P, Auligné T, Bell W, Geer A, Guidard V, Heilliette S, Kazumori M, Kim MJ, Liu EHC, McNally AP, Macpherson B, Okamoto K, Renshaw R, Riishøjgaard LP. 2011. Satellite cloud and precipitation assimilation at operational NWP centres. Q. J. R. Meteorol. Soc. 137: 1934-1951, DOI: 10.1002/qj.905.

Bell W, Candy B, Atkinson N, Hilton F, Baker N, Bormann N, Kelly G, Kazumori M, Campbell WF, Swadley SD. 2008. The assimilation of SSMIS radiances in numerical weather prediction models. IEEE Trans. Geosci. Remote Sensing 46: 884-900, DOI: 10.1109/TGRS.2008.917335.

Capderou M. 2005. Satellites: Orbits and Missions. Springer: Paris.

Chambon P, Jobard I, Roca R, Viltard N. 2012. An investigation of the error budget of tropical rainfall accumulation derived from merged passive microwave and infrared satellite measurements. Q. J. R. Meteorol. Soc. 139: 879-893, DOI: 10.1002/qj.1907.

Dee DP. 2004. 'Variational bias correction of radiance data in the ECMWF system'. In Proceedings of the ECMWF Workshop on Assimilation of High Spectral Resolution Sounders in NWP, 28 June-1 July 2004. Reading, UK.

Dee DP. 2005. Bias and data assimilation. Q. J. R. Meteorol. Soc. 131:3323-3343 DOI: 10.1256/qj.05.137.

Desroziers G, Ivanov S. 2001. Diagnosis and adaptive tuning of observationerror parameters in a variational assimilation. Q. J. R. Meteorol. Soc. 127: 1433-1452, DOI: 10.1002/qj.49712757417.

English SJ. 2008. The importance of accurate skin temperature in assimilating radiances from satellite sounding instruments. IEEE Trans. Geosci. Remote Sensing 46: 403-408, DOI: 10.1109/TGRS.2007.902413.

Errico RM, Bauer P, Mahfouf JF. 2007. Issues regarding the assimilation of cloud and precipitation data. J. Atmos. Sci. 64: 3785-3798, DOI: 10.1175/2006JAS2044.1.

Gaspari G, Cohn SE. 1999. Construction of correlation functions in two and three dimensions. Q. J. R. Meteorol. Soc. 125: 723-757, DOI: 10.1002/qj.49712555417.

Geer AJ, Bauer P. 2011. Observation errors in all-sky data assimilation. Q. J. R. Meteorol. Soc. 137: 2024-2037, DOI: 10.1002/qj.830.

Grody N. 1991. Classification of snow cover and precipitation using the special sensor microwave imager. J. Geophys. Res. 96: 7423-7435, DOI: 10.1029/91JD00045.

Hou AY, Zhang SQ. 2007. Assimilation of precipitation information using column model physics as a weak constraint. J. Atmos. Sci. 64: 3865-3878, DOI: $10.1175 / 2006 J A S 2028.1$. 
Hou AY, Zhang SQ, Reale O. 2004. Variational continuous assimilation of TMI and SSM/I rain rates: impact on GEOS-3 hurricane analyses and forecasts. Mon. Weather Rev. 132: 2094-2109, DOI: 10.1175/1520-0493(2004)132 2094:vcaota 2.0.CO;2.

Hou AY, Jackson GS, Kummerow C, Shepherd JM. 2008. Global precipitation measurement. In Precipitation: Advances in Measurement, Estimation, and Prediction, Michaelides S (ed.): 131-170. Springer: Berlin.

Johnson BT, Petty GW, Skofronick-Jackson G. 2012. Microwave properties of ice-phase hydrometeors for radar and radiometers: Sensitivity to model assumptions. J. Appl. Meteorol. Clim. 51: 2152-2171, DOI: 10.1175/JAMCD-11-0138.1.

Kirstetter PE, Delrieu G, Boudevillain B, Obled C. 2010. Toward an error model for radar quantitative precipitation estimation in the Cévennes-Vivarais region, France. J. Hydrol. 394: 28-41, DOI: 10.1016/j.jhydrol.2010.01.009.

Kummerow C, Olson WS, Giglio L. 1996. A simplified scheme for obtaining precipitation and vertical hydrometeor profiles from passive microwave sensors. IEEE Trans. Geosci. Remote Sensing 34: 1213-1232, DOI: $10.1109 / 36.536538$

Lang SE, Tao WK, Zeng X, Li Y. 2011. Reducing the biases in simulated radar reflectivities from a bulk microphysics scheme: tropical convective systems. J. Atmos. Sci. 68: 2306-2320, DOI: 10.1175/JAS-D-10-05000.1.

Liu G. 2008. A database of microwave single-scattering properties for nonspherical ice particles. Bull. Am. Meteorol. Soc. 89: 1563-1570, DOI: 10.1175/2008BAMS2486.1

Lopez P. 2011. Direct 4D-Var assimilation of NCEP stage IV radar and gauge precipitation data at ECMWF. Mon. Weather Rev. 139: 2098-2116, DOI: 10.1175/2010MWR3565.1.

Mahfouf JF, Bauer P, Marécal V. 2005. The assimilation of SSM/I and TMI rainfall rates in the ECMWF 4D-Var system. Q. J. R. Meteorol. Soc. 131 437-458, DOI: 10.1256/qj.04.17.

Marécal V, Mahfouf JF. 2002. Four-dimensional variational assimilation of total column water vapor in rainy areas. Mon. Weather Rev. 130: 43-58, DOI: 10.1175/1520-0493 (2002)130 0043:fdvaot 2.0.CO;2.

Matsui T, Zeng X, Tao WK, Masunaga H, Olson WS, Lang S. 2009. Evaluation of long-term cloud-resolving model simulations using satellite radiance observations and multifrequency satellite simulators. J. Atmos. Oceanic Technol. 26: 1261-1274, DOI: 10.1175/2008JTECHA1168.1.

Michel Y, Auligné T, Montmerle T. 2011. Heterogeneous convective-scale background error covariances with the inclusion of hydrometeor variables. Mon. Weather Rev. 139: 2994-3015, DOI: 10.1175/2011MWR3632.1.

Mitchell HL, Houtekamer PL, Pellerin G. 2002. Ensemble size, balance, and model-error representation in an ensemble Kalman filter. Mon. Weathe Rev. 130: 2791-2808, DOI: 10.1175/1520-0493(2002)130 2791:esbame2.0. $\mathrm{CO} ; 2$

Petty G, Huang W. 2010. Microwave backscatter and extinction by soft ice spheres and complex snow aggregates. J. Atmos. Sci. 67: 769-787, DOI: 10.1175/2009JAS3146.1.

Pincus R, Hofmann RJP, Anderson JL, Raeder K, Collins N, Whitaker JS. 2011. Can fully accounting for clouds in data assimilation improve short-term forecasts by global models? Mon. Weather Rev. 139: 946-957, DOI 10.1175/2010MWR3412.1

Roca R, Chambon P, Jobard I, Kirstetter PE, Gosset M, Bergès IC. 2010. Comparing satellite and surface rainfall products over West Africa at meteorologically relevant scales during the AMMA campaign using error estimates. J. Appl. Meteorol. Climatol. 49: 715-731, DOI: 10.1175/2009JAMC2318.1.
Sapiano MRP, Berg WK, McKague DS, Kummerow CD. 2012. Toward an intercalibrated fundamental climate data record of the SSM/I sensors. IEEE Trans. Geosci. Remote Sensing 99: 1-12, DOI: 10.1109/TGRS.2012.22 06601.

Schwartz CS, Liu Z, Chen Y, Huang X. 2012. Impact of assimilating microwave radiances with a limited-area ensemble data assimilation system on forecasts of Typhoon Morakot. Weather and Forecasting 27: 424-437, DOI: 10.1175/WAF-D-11-00033.1.

Skamarock WC, Klemp JB, Dudhia J, Gill DO, Barker DM, Wang W, Powers JG. 2005. 'A description of the advanced research WRF version 2', Technical Note NCAR/TN-468+STR. NCAR: Boulder, CO, 88 pp.

Tabary P. 2007. The new French operational radar rainfall product. Part I: methodology. Weather and Forecasting 22: 393-408, DOI: 10.1175/WAF1004.1.

Tabary P, Desplats J, Do Khac K, Eideliman F, Gueguen C, Heinrich JC. 2007. The new French operational radar rainfall product. Part II: Validation. Weather and Forecasting 22: 409-427, DOI: 10.1175/WAF1005.1.

Talagrand O. 1999. 'A posteriori verification of analysis and assimilation algorithms'. In Proceedings of the ECMWF Workshop on Diagnosis of Data Assimilation Systems, 2-4 November 1999. Reading, UK.

Tao WK. 2003. Goddard Cumulus Ensemble (GCE) model: Application for understanding precipitation processes. Meteorol. Monogr. 29: 107-107, DOI: 10.1175/0065-9401(2003)029 0107:cgcegm 2.0.CO;2.

Weng Y, Zhang F. 2012. Assimilating airborne Doppler radar observations with an ensemble Kalman filter for convection-permitting hurricane initialization and prediction: Katrina (2005). Mon. Weather Rev. 140: 841-859, DOI: 10.1175/2011MWR3602.1.

Weng F, Yan B, Grody NC. 2001. A microwave land emissivity model. J. Geophys. Res. 106(:): 20115-20123, DOI: 10.1029/2001JD900019.

Wilheit T, Kummerow CD, Ferraro R. 2003. NASDARainfall algorithms for AMSR-E. IEEE Trans. Geosci. Remote Sensing 41: 204-214, DOI: 10.1109/TGRS.2002.808312.

Yang SC, Kalnay E, Hunt B, Bowler EN. 2009. Weight interpolation for efficient data assimilation with the Local Ensemble Transform Kalman Filter. Q. J. R. Meteorol. Soc. 135: 251-262, DOI: 10.1002/qj.353.

Zhang M, Zhang F. 2012. E4DVar: Coupling an Ensemble Kalman filter with four-dimensional variational data assimilation in a limited-area weather prediction model. Mon. Weather Rev. 140: 587-600, DOI: 10.1175/MWRD-11-00023.1.

Zhang SQ, Zupanski M, Hou AY, Lin X, Cheung SH. 2013. Assimilation of precipitation-affected radiances in a cloud-resolving WRF ensemble data assimilation system. Mon. Weather Rev. 141: 754-772 DOI: 10.1175/MWRD-12-00055.1.

Zupanski M. 2005. Maximum likelihood ensemble filter: Theoretical aspects. Mon. Weather Rev. 133: 1710-1726, DOI: 10.1175/MWR2946.1.

Zupanski M, Navon IM, Zupanski D. 2008. The Maximum Likelihood Ensemble Filter as a non-differentiable minimization algorithm. Q. J. R. Meteorol. Soc. 134: 1039-1050, DOI: 10.1002/qj.251.

Zupanski D, Zupanski M, Grasso LD, Brummer R, Jankov I, Lindsev D, Sengupta M, Demaria M. 2011a. Assimilating synthetic GOES-R radiances in cloudy conditions using an ensemble-based method. Int. J. Remote Sensing 32: 9637-9659, DOI: 10.1080/01431161.2011.572094.

Zupanski D, Zhang SQ, Zupanski M, Hou AY, Cheung SH. 2011b. A prototype WRF-based ensemble data assimilation system for dynamically downscaling satellite precipitation observations. J. Hydrometeorol. 12: 118-134, DOI: 10.1175/2010JHM1271.1. 